\title{
A Review of Optimal Planning Active Distribution System: Models, Methods, and Future Researches
}

\author{
Rui Li ${ }^{1,2}{ }^{*}$, Wei Wang ${ }^{1,2}$, Zhe Chen ${ }^{3}$, Jiuchun Jiang ${ }^{1,2}$ and Weige Zhang ${ }^{1,2}$ \\ 1 National Active Distribution Network Technology Research Center (NANTEC), Beijing JiaoTong University, \\ Beijing 100044, China; wwang2@bjtu.edu.cn (W.W.); jcjiang@bjtu.edu.cn (J.J.); wgzhang@bjtu.edu.cn (W.Z.) \\ 2 Collaborative Innovation Center of Electric Vehicles in Beijing, Beijing 100081, China \\ 3 Department of Energy Technology, Aalborg University, DK9220 Aalborg, Denmark; zch@et.aau.dk \\ * Correspondence: lirui_ee@bjtu.edu.cn
}

Received: 24 August 2017; Accepted: 24 October 2017; Published: 26 October 2017

\begin{abstract}
Due to the widespread deployment of distributed energy resources (DERs) and the liberalization of electricity market, traditional distribution networks are undergoing a transition to active distribution systems (ADSs), and the traditional deterministic planning methods have become unsuitable under the high penetration of DERs. Aiming to develop appropriate models and methodologies for the planning of ADSs, the key features of ADS planning problem are analyzed from the different perspectives, such as the allocation of DGs and ESS, coupling of operation and planning, and high-level uncertainties. Based on these analyses, this comprehensive literature review summarizes the latest research and development associated with ADS planning. The planning models and methods proposed in these research works are analyzed and categorized from different perspectives including objectives, decision variables, constraint conditions, and solving algorithms. The key theoretical issues and challenges of ADS planning are extracted and discussed. Meanwhile, emphasis is also given to the suitable suggestions to deal with these abovementioned issues based on the available literature and comparisons between them. Finally, several important research prospects are recommended for further research in ADS planning field, such as planning with multiple micro-grids (MGs), collaborative planning between ADSs and information communication system (ICS), and planning from different perspectives of multi-stakeholders.
\end{abstract}

Keywords: distributed energy resources; planning model; active distribution system; distribution network planning; optimization program

\section{Introduction}

For the purpose of security of energy supply and sustainability of energy utilization, renewable energy technology has experienced a rapid development all over the world. At present, renewable energy sources (RESs) share about $5 \%$ and $13 \%$ of electricity power supply in the United States of America (USA) and the European Union (EU), respectively [1]. With the promoting of "20-20-20", RESs have been greatly developed and advanced in many European countries. In Denmark, for instance, more than $42 \%$ of the load demand is supplied by wind power in 2015 , where a $100 \%$ renewable energy future by 2050 is targeted [2].

Among them, plenty of renewable distributed generations (RDGs), especially distributed photovoltaic (DPVs), and distributed wind generations (DWGs), have been integrated into distribution networks. However, due to the natures of intermittent and difficult prediction, RDGs pose new challenges to distribution networks on several fronts, such as planning, design, and operation [3,4]. In this regard, ADS is introduced and perceived to be one of key technologies to alleviate aforementioned challenges [5-8]. 
The deterministic methods and the strategy of "fit and forget" are always adopted to deal with integration of RDGs in traditional planning of distribution networks based on the worst and low-probability scenarios, which ignores the uncertainties of RDGs and the different operation conditions. With the widespread use of distributed energy resources (DERs), the drawbacks of these deterministic methods have been increasingly emerging, such as unnecessary distribution grid reinforcements, increasing network losses, and unattainable development and environmental targets. Therefore, traditional planning methods have become barriers to improve the penetration of DERs and are no longer valid in ADS planning.

ADS planning is a complex and comprehensive mission, which needs to give not only the planning scheme of distribution networks, but also the allocation of DERs in the most economic, reliable, and safe way [9-12]. In the meanwhile, high-level uncertainties, coming from DERs, networks, and load demand, etc., increase the complexity of planning model and difficulty of finding a solution. In addition, comparing with traditional planning methods, ADS planning tools need to provide more comprehensive planning analyses from several different criteria, such as economic criterion, technical criterion and environmental criterion, in a multi-objective approach.

Optimal planning of ADS has caught the attention of researchers, and plenty of planning models and methodologies with bright characters and reference significances have emerged. In the meanwhile, several influential and noticeable reviews of optimal planning of distribution networks have been published [13-20]. In [13], authors offer a comprehensive review of the planning of smart distribution networks from the perspectives of intelligent technologies, anticipated functionalities, modern distribution concepts, policies, plans, and policies. The real world optimization problems are investigated considering multi-objective problem and multi-stakeholders in the literature review. In [14], an extended review on the planning of distribution networks is given and the differences between traditional distribution networks planning models and active planning models are discussed. Moreover, a generic multi-dimensional framework for optimal active distribution network planning is proposed to overcome the limitations of the current researches. In [15], 77 selected papers that were published from 2007 to 2014 are reviewed from perspectives of planning models and solving methods to analyze and classify the current research status of distribution networks planning problems. After that, several crucial research areas are introduced briefly to identify the future research trends of this filed. Kazmi et al. [16] also focuses on the planning problem of distribution networks, and especially provides a comprehensive review about the multi-objective models and solving algorithms in this filed. Furthermore, potential future directions in modern distribution networks planning from a multi-objective perspective have also been highlighted. Different from these review articles, many scholars [17-19] review and summary the literature about the allocation of distributed generations (DGs) and energy storage systems (ESSs) in distribution networks, respectively.

Aiming to provide a guide to distribution system, engineers and researchers on the ADS planning especially from the point view of planning models and solving algorithms, the selected articles in the field of distribution network planning published from 2010 [21-107] are reviewed in this paper. To clarify the latest research achievements, the research achievements published in the last three years accounts for more than half of these selected articles. The planning models and methods proposed in these articles are analyzed and categorized from different perspectives including objectives, decision variables, constraint conditions, and solving algorithms. At the same time, the emphasis is also given on the key theoretical issues and challenges of planning models and methodologies, which are extracted and discussed together with several suitable suggestions, including methods to deal with high-level uncertainties, methods to incorporate operational aspects into planning, integration of ESSs and DR, and methods to deal with multiple time scales. Moreover, based on the review, this paper also provides several recommended research prospects for the guidance of further research in details.

The paper is organized as follows. Section 2 analyzes the key features of ADS planning. Section 3 focuses on the analyses on models and methods of ADS planning. In Section 4, several key theoretical issues and challenges in the ADS planning are extracted and discussed. After that, several 
recommended research prospects are further given in Section 5. Then, Section 6 concludes this paper with several remarks of summary.

\section{Key Features of ADS Planning}

\subsection{Definition of ADS}

The CIGRE introduced the concept of active distribution network (ADN) in 2008; ADNs have systems in place to control a combination of DERs, defined as generators, loads, and storage, where distribution system operators (DSOs) have the possibility of managing the electricity flows using a flexible network topology. DERs take some degree of responsibility for system support, which depends on suitable regulatory environments and connection agreements [9]. In 2012, due to the increasing penetration of DERs, the concept of ADN was extended to ADS [10]. At present, the basic definition and framework of ADS have been well acknowledged by other important academic organization, such as IEEE and CIRED [11,12].

The transformation from traditional distribution networks to ADNs indicates that DERs are no longer integrated passively, but controlled actively and coordinated to improve the utilization of DERs. Moreover, due to the increasing penetration of DERs, the transformation from ADNs to ADSs indicates that ADSs are no longer be considered as just the distribution grids to deliver electric power to the consumers, but the compositive systems including DGs, active networks, dynamical active and flexible load demand, ESSs, and etc.

\subsection{Features of ADS Planning}

It is obvious that comparing with the planning of traditional distribution networks, both the definition and the connotation of ADS planning have been developed with the following key features.

\subsubsection{Optimal Allocation of DGs}

Due to the increasing penetration of DGs, the optimal allocation of DGs has become an important part of ADS planning and serves as a crucial available solution to satisfy load growth. If these resources are integrated optimally, many benefits can be obtained, including deferring network upgrade, improving asset utilization, reducing network energy losses, and enhancing system reliability $[25,34,50,108]$.

In order to guarantee the secure and stable operation, DGs should be allocated to satisfy the security constraints of distribution networks. Therefore, the allocation of DGs and planning of networks should be optimized coordinately $[45,61,64,87]$.

\subsubsection{Coupling of Operation and Planning}

Different from the strategy of "fit and forget", active managements (AMs) adopted in ADS enable DERs be controlled and managed cooperatively to tackle aforementioned challenges [10], as shown in Figure 1.

As shown in Figure 1, with the wide spread of fluctuate REGs and dynamical active load demand in ADSs, the effects of voltage rise/drop at their points of common coupling will be worsen, especially in rural distribution networks. It is one of the main barriers that limit the hosting capacity for dynamic active load demand and the accommodation ability for DDGs and RDGs [109]. Meanwhile, the extensive integration of various types of DGs and power electronic devices also affects the features of reactive power flow in networks. The ordinary reactive power supply such as capacitor banks are not capable of satisfying the demand of reactive power supply and voltage control adequately. Furthermore, the integration of DGs and power electronic devices with high renewable penetration will also impact the fault level brought by bi-direction fault currents, and complicate the fault conditions caused by internal faults of DGs and islanded operation of DGs [12]. 


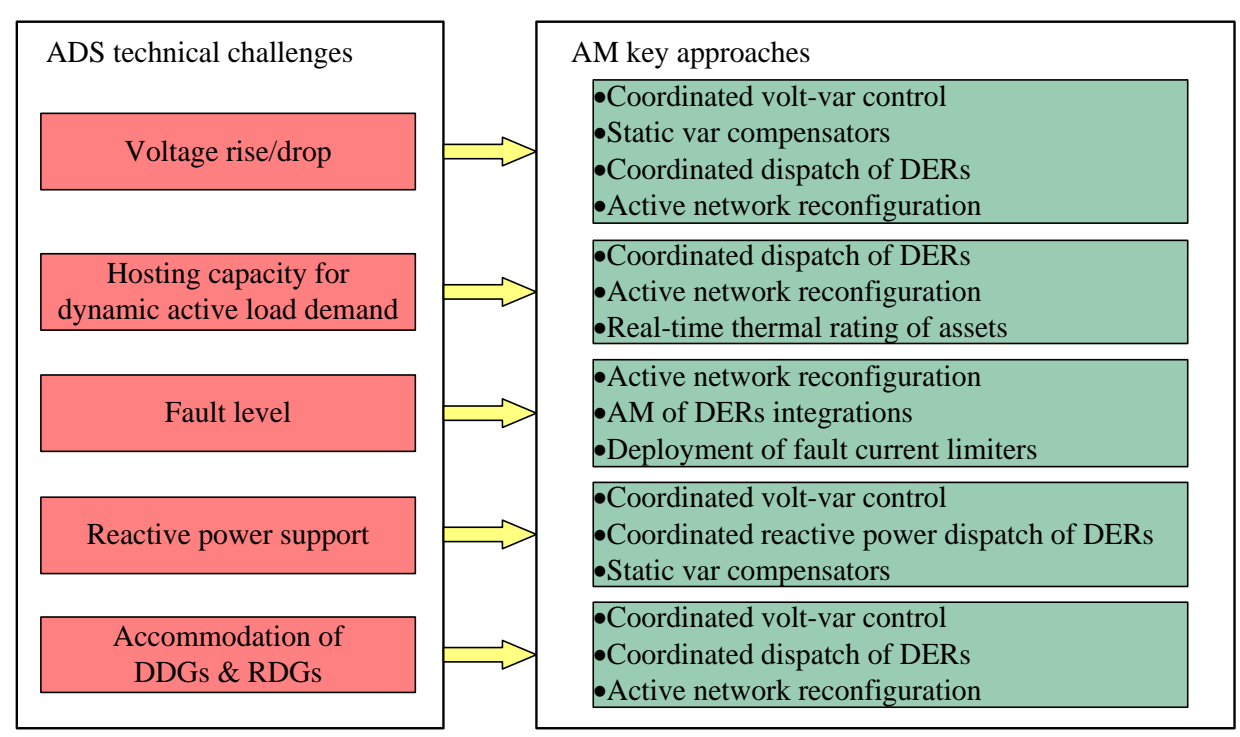

Figure 1. Technical challenges and corresponding active managements (AM) key approaches.

Aiming to addressing these undesirable conditions, several AM key approaches are introduced and listed in Figure 1. All these AM approaches, such as active network reconfiguration [35,77,97,110], coordinated volt-var control [98,109], coordinated dispatch of DERs, including DGs [22,52,94], ESSs $[46,71,88,111]$, demand response (DR) $[53,65,89,112]$, and optimal charging strategy of electric vehicles (EVs) [55,99], offer many potential benefits to the planning of ADSs and affect quality of the planning solution. The coupling of operation and planning is able to achieve the simultaneous optimization of planning and operation, and to identify the benefits and the effects of optimal operation on the planning solution. Therefore, operation models of AMs should be integrated into planning models to defer or avoid network expansion or reinforcement.

\subsubsection{High-Level Uncertainties}

High proportion of DERs integration makes ADS planning methods take comprehensive account of high-level uncertainties which come from several aspects, including DGs, networks, load demand, and wholescale market, as shown as Figure 2.

All of these aspects of high-level uncertainties have a great influence on the planning models and solving algorithms. Moreover, the combined effects among these uncertainties may further aggravate the aforementioned influence.

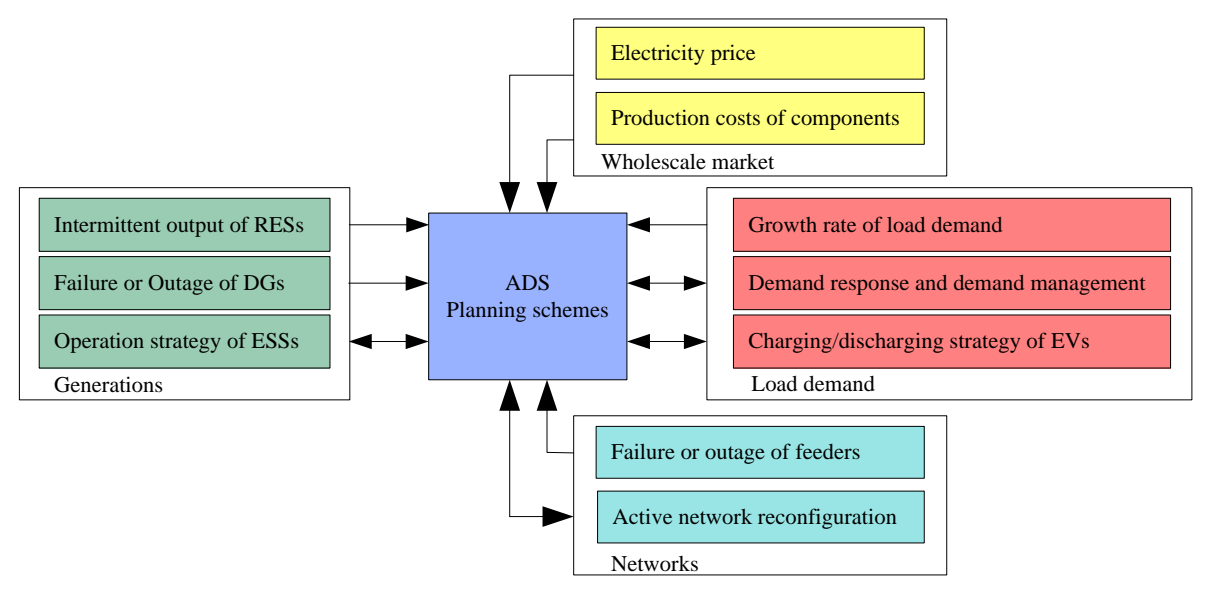

Figure 2. Multiple aspects of high-level uncertainties. 


\subsubsection{Optimal Allocation of ESSs}

Thanks to the flexibility of power regulation, ESSs perform multiple important roles in ADSs, including peak load shaving and valley load filling [90], network upgrade deferral [93,105], frequency-voltage control [46], power quality and reliability improvement [20,60,78,101,104,105], alleviating the fluctuation of RDGs [46], obtaining arbitrage benefit [60,105], reducing energy losses [60], and providing a time varying power energy management, etc.

Therefore, the allocation of ESSs (sizing and sitting) has a great impact on the ADS planning and has been perceived to be one of indispensable parts of ADS planning [67].

\subsubsection{Multiple Objective Approach}

When it comes to traditional distribution networks, economic criterion is always adopted to be the optimization objective for selecting planning schemes. However, there are more objectives for ADS planning.

In ADS, due to the natures of intermittency and difficult prediction, DERs' integration poses great challenges for secure and stable operation of ADS. In the meanwhile, more and more electric devices require higher power quality. Therefore, the system reliability and power quality have become crucial objectives for ADS planning.

Moreover, the limited utilization of the installed renewable source based power generators has become too severe to increase the penetration of RDGs, and the wind/solar power curtailment has become a frequent occurrence. The environmental and economic benefits brought by RDGs are greatly reduced. Therefore, how to improve the penetration and utilization of RDGs should be integrated into the planning targets.

On the whole, ADS planning is a multi-objective optimal problem for both planning of networks and allocations of DERs under the conditions of high-level uncertainties, in process of which operation models of AMs are integrated into ADS planning for the purpose of increasing economic efficiency, enhancing system reliability, and improving the utilization of RDGs.

\section{ADS Planning Model}

\subsection{Problem Formulation}

The optimal mathematic model of ADS planning is similar to traditional distribution network planning, which can be formulated as a typical optimization problem. However, comparing with the traditional one, there are more decision variables, more comprehensive objectives, more complex constraints, and higher level uncertainties in ADS planning models. The basic mathematic model of ADS planning is shown as:

$$
\begin{aligned}
& \min F\left(x_{s t}, y_{s t}\right)=\left[O F_{1}, O F_{2}, \ldots, O F_{M}\right] \\
& \text { s.t. }\left\{\begin{array}{l}
G\left(x_{s t}, y_{s t}\right)=0 \\
H\left(x_{s t}, y_{s t}\right) \leq 0 \\
1 \leq s t \leq N_{S T}
\end{array}\right.
\end{aligned}
$$

where, $x_{s t}, y_{s t}$ are the decision variables for planning networks and allocations of DERs, including possible network topologies, possible locations, sizes and types of substations and DERs. $O F_{1}, O F_{2}, \ldots, O F_{M}$, are the optimal objectives of planning model, such as investment, maintenance and operation costs, indexes of reliability, and power curtailment level of RDGs. $G($.$) and H($.$) are the equality constraints and$ inequality constraints. Moreover, $N_{\mathrm{ST}}$ is the number of planning stage; when $N_{\mathrm{ST}}=1$, the planning model is a static planning model, otherwise the model is a dynamic multi-stage planning model. 


\subsection{Decision Variables}

The decision variables of ADS planning consist of the variables of traditional distribution networks, as well as the additional variables of DERs, as shown in Table 1 . The distribution of decision variables in these surveyed papers is shown in Figures 3 and 4.

Table 1. Decision variables of ADS planning models.

\begin{tabular}{|c|c|c|}
\hline Types & Decision Variables & References \\
\hline \multirow{5}{*}{$\begin{array}{l}\text { Traditional } \\
\text { variables }\end{array}$} & Locations and sizes of new substations & {$[26,29,30,32,36,38,54,55,58,66,80,85,89]$} \\
\hline & $\begin{array}{l}\text { Sizes of existing substations for } \\
\text { reinforcement }\end{array}$ & $\begin{array}{l}{[24,26,27,29,32,34,36,38,42,52,54,58,64,66,} \\
73,80,85,89,95,96,99]\end{array}$ \\
\hline & Locations and sizes of new feeders & $\begin{array}{l}{[24,26,28-32,38,39,43,49,50,54-56,58,63,66,} \\
71,74,80,84,85,89,91,106]\end{array}$ \\
\hline & $\begin{array}{l}\text { Sizes of existing feeders for } \\
\text { reinforcement }\end{array}$ & $\begin{array}{l}{[21,23,24,26,27,29,31,34-37,41-43,48-50} \\
52,53,59,66,67,71,73,75,81,84,86,95,96,99]\end{array}$ \\
\hline & $\begin{array}{l}\text { Locations of reserve feeders and } \\
\text { interconnection switches }\end{array}$ & {$[23,24,28,29,31,32,36,38,50,66,81,82,101]$} \\
\hline \multirow{5}{*}{$\begin{array}{l}\text { Additional } \\
\text { variables }\end{array}$} & $\begin{array}{l}\text { Locations, sizes, and types of } \\
\text { dispatchable distributed generations } \\
\text { (DDGs) }\end{array}$ & $\begin{array}{l}{[23-25,27,31-35,38-43,45,48,50,61,66,72,} \\
77,81,83,84,86,96,97,100,102]\end{array}$ \\
\hline & Locations, sizes, and types of RDGs & $\begin{array}{l}{[22,25,34,35,44,48,51,53,58,62,64-66,68,74-} \\
76,79,81,88,89,93,98,99,103,107]\end{array}$ \\
\hline & $\begin{array}{l}\text { Locations of new dynamic active load } \\
\text { demand (e.g., charging station of EVs) }\end{array}$ & {$[23,47,54,55,78,80,82,85]$} \\
\hline & $\begin{array}{l}\text { Locations, sizes, and types of } \\
\text { centralized/distributed ESSs }\end{array}$ & $\begin{array}{l}{[32,46,57,60,69-72,75,83,87,90,92,94,101,} \\
104,105]\end{array}$ \\
\hline & $\begin{array}{l}\text { Locations and sizes of voltage control } \\
\text { devices (e.g., capacitor banks and Static } \\
\text { var compensator (SVC)) }\end{array}$ & {$[37,41,52,63,68,75,77,79,88,96]$} \\
\hline
\end{tabular}

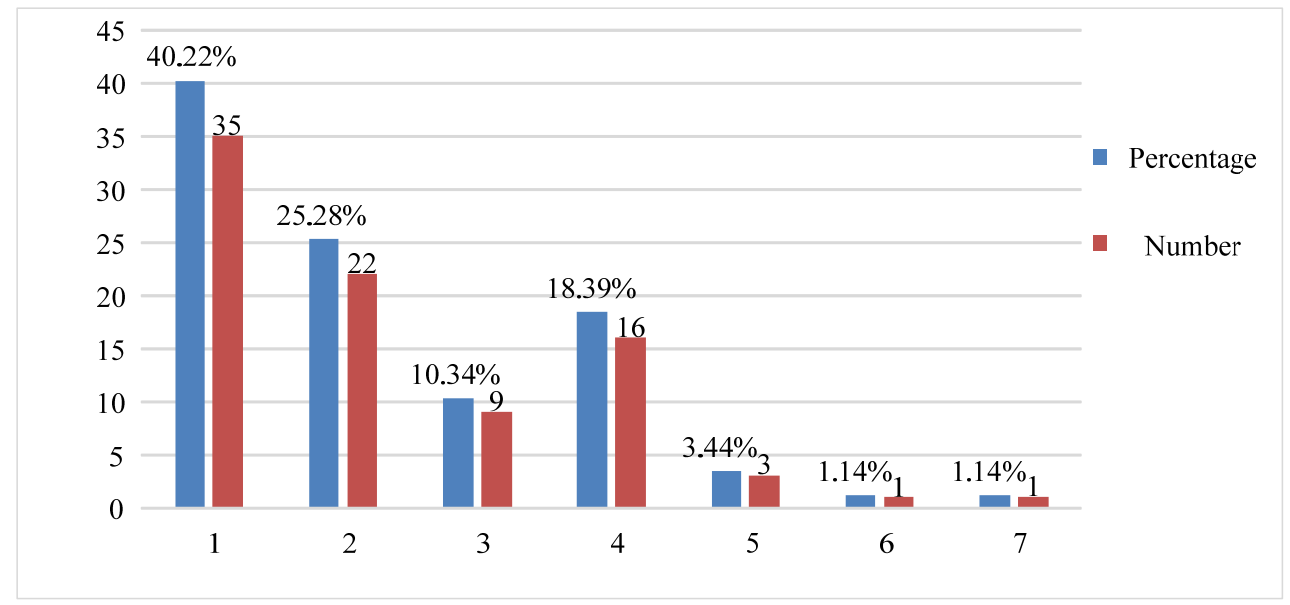

Figure 3. Distribution of the considered numbers of decision variables. 


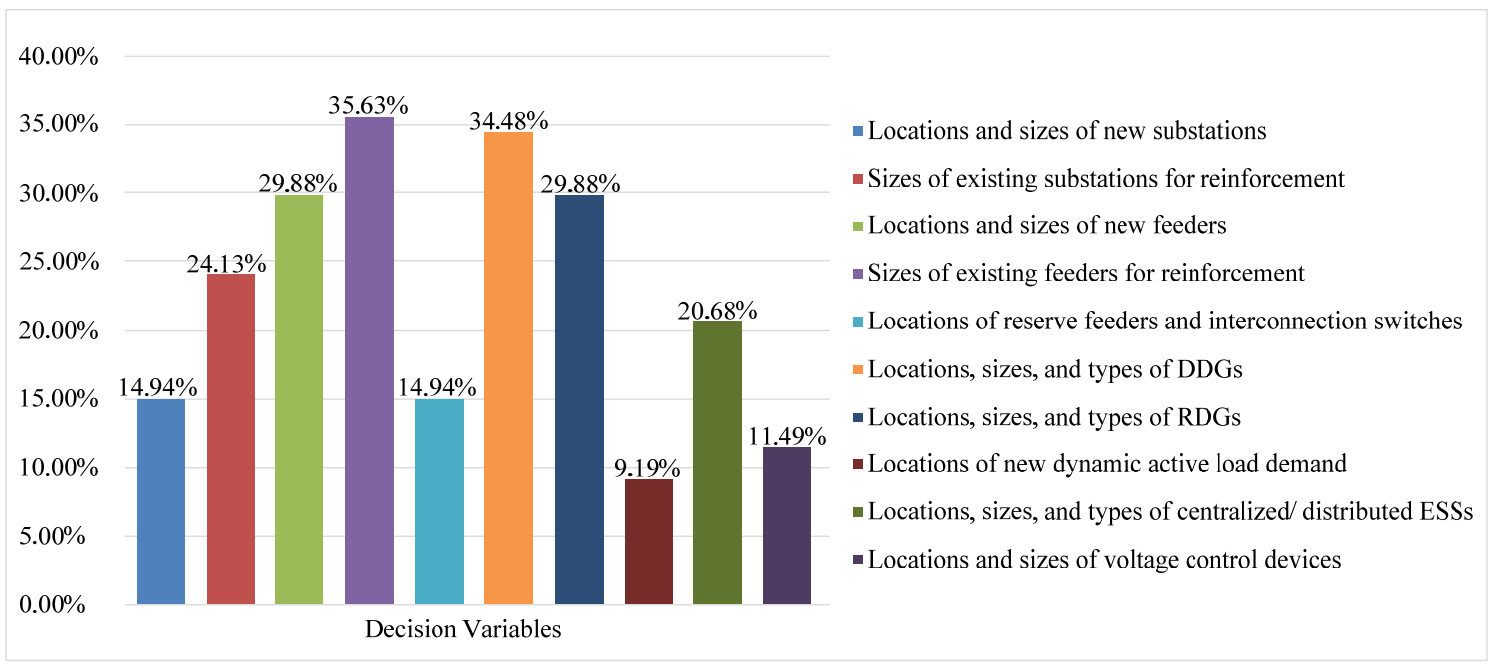

Figure 4. Distribution of decision variables in the literature survey.

Based on the results shown in Figure 3, the numbers of decision variables in most of these articles are smaller than 5 . That is because the increase of variable number will complicate the planning problem and aggravate the calculation burden of planning models. The planning model proposed in [66] is the only one involving seven decision variables to satisfy load growth, including optimal reinforcement of existing feeders and substations, or installation new ones, locations of reserve feeders, and optimal locations and sizes of DDGs and RDGs. In [32], the optimal allocations of ESSs and DDGs are integrated into distribution network expansion planning model and serve as the decision variables together with the planning of existing feeders, substations and new ones. In the process of planning, the roles of ESSs are taken into consideration including peak load shaving and reliability improvement. But the integrated planning model does not involve the allocation of RDGs.

Among these decision variables in Table 1, the variables of (1) reinforcement of existing feeders; (2) allocations of DDGs; (3) locations and sizes of new feeders; and, (4) allocations of RDGs, have attracted the most attention. Articles involving these four decision variables account for $35.63 \%$, $34.48 \%, 29.88 \%$, and $29.88 \%$, respectively. On the contrary, few of these papers take the variables of (1) locations of reserve feeders and interconnection switches; (2) allocation of voltage control devices; and, (3) new dynamic active load demand into consideration. However, it is worth noting that these three variables are associated with AM approaches of active network reconfiguration, coordinated volt-var control, and DR, respectively. It means that, to some extent, these three AM approaches have not received sufficient attentions, which will hinder integration and utilization of DERs.

In $[23,24,28,31,32,36,38,50,66,81,101]$, optimal locations of reserve feeders and switches are introduced into the ADS planning model to improve system reliability and reduce the financial loss brought by interrupted power supply. Different from these papers, an optimal allocation model of EVs charging station is proposed in [82], where the optimal allocation of tie lines is considered to alleviate load capability constraints in networks. The AM approach of active network reconfiguration is also beneficial to improve RES hosting capacity.

In [75], an ADS planning model is proposed to determine optimal allocation of RDGs, ESSs, and capacitor banks, as well as enforcement schemes of networks. The planning results suggest that optimal allocations of ESSs and capacitors are beneficial to improving penetration and utilization level of RDGs and achieving the upgrade deferral. Similar with [75], the benefits brought by optimal allocation of voltage control devices on accommodation of RDGs are also verified in $[41,68,79,88,96]$. 


\subsection{Planning Objectives}

The planning objectives of ADS can be classified as economic objectives, technical objectives, and environmental objectives. Figure 5 provides several primary planning objectives, and other objectives not on the list are always the deformations of these primary objectives. Figure 6 provides the information about number of objectives.

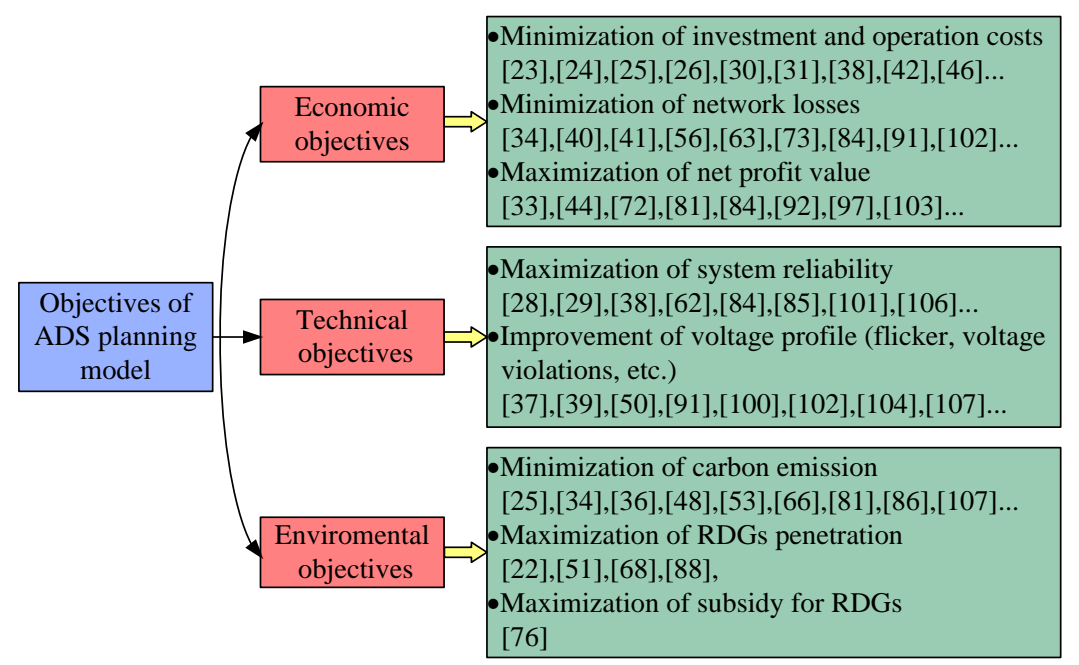

Figure 5. Planning objectives of ADS.

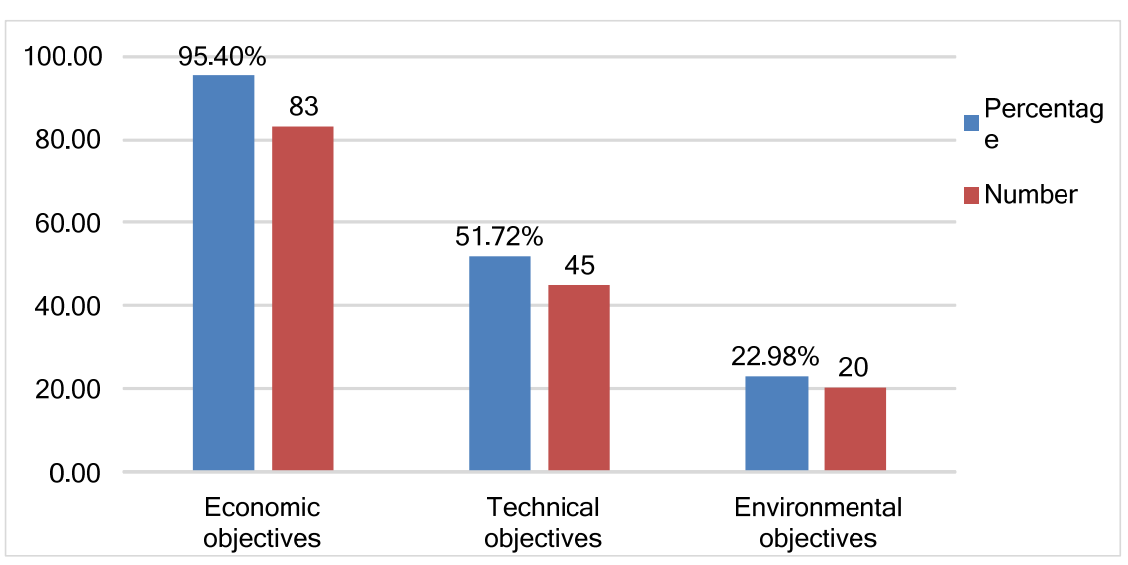

Figure 6. Distribution of the considered numbers of planning objectives.

As shown in Figure 6, economic objectives are the most common planning objectives, and $95.40 \%$ of the surveyed papers involve economic objectives. On the contrary, only $22.98 \%$ of these planning models focus on the environmental objectives.

Moreover, $71 \%$ of the surveyed papers take the single objective planning approach and the rest are multiple objective models. Although more than $53 \%$ of these single objective models also involve the technical and/or environmental factors, all of these factors are converted to economic ones by economic parameters, such as reliability costs $[24,31,32,34,36,41-43,56,60,63,64,66,71,75,76,87,91]$ and emission costs $[25,34-36,48,53,66,75,81,86,92,94,107]$. However, these economic parameters are always experience dependent, and may affect the objectivity of planning solutions.

At present, the methods to deal with multiple objective planning models can be classed as the weight coefficient methods and the Pareto-based methods.

1. Weight coefficient methods, where the multi-objective model is transformed into a single objective model by means of weight coefficients. Several approaches are adopted to determine these weight 
coefficients for each objective, such as user-defined fixed weight [39,65], analytic hierarchy process [57,107], stochastic weights [63], fuzzing mathematics method [83], and bargaining function [85]. These weight coefficient methods with a priori articulation of preferences have the advantages of simplicity and convenience, but have the drawback of subjectivity at the same time.

2. Pareto-based methods, where a Pareto-optimal set or a Pareto-optimal frontier, can be obtained by means of non-dominated ranking algorithm to deal with candidate solutions. The most important advantage of this method with a posteriori articulation of preferences is that all the different objectives can be taken into account with equal attention. A set of optimal solutions can be made as available options for decision-makers from different perspectives. As a result, more than $68 \%$ of these aforementioned multi-objective planning methodologies adopt this approach to deal with multiple objectives. However, comparing with weight coefficient methods, more computation time and computational memory are required for Pareto-based methods.

\subsection{Constraints}

In order to grantee the feasibility of planning solutions, many aspects of equality and inequality constraint conditions must be strictly obeyed in ADS planning formulation, including technical, economic, and installation conditions.

The most common technical constraints include: (1) radial operation of networks and full connectivity; (2) size limits of substations and feeders; (3) power flow equality constraints; (4) active/reactive power balance equations; (5) permissible range of bus voltage magnitude; (6) position limits on-load tap changer (OLTC); (7) ramp constraints of DDGs; (8) power production constraints of DDGs and RDGs; (9) operation constraints of ESSs; and, (10) operation constraints of DR. It is noteworthy that constraints 7 to constraint 10 are the additional ones for ADSs, and constraint 2 and constraint 5 are the main obstacles to increase the penetration of DERs.

The economic constraints mainly refer to the budget limits for DSOs to build substations and feeders, and budget limits for distributed generation operators (DGOs) and DSOs to install DGs. Moreover, some articles, such as [33], introduce the constraints of maintaining positive profit for each individual DG investor to make the investment more attractive.

Additionally, installation condition constraints mean the geographical condition, landscape aesthetics constraints to install DGs, such as DWGs, DPVs, gas turbine, and gas transmission pipeline.

\subsection{Solving Algorithms}

Based on the above analyses, most of the proposed planning models are complex mixed integer nonlinear optimization problem with multiple decision variables and multiple constraint conditions, which poses a great challenge to the solving algorithms. How to obtain the optimal planning solutions and keep high computational efficiency is one of the key ADS planning issues.

There are two main classes of algorithms to solve these planning models, including the numerical methods and the heuristic methods. The adoption situations of different algorithms are provided in Figure 7. It can be seen that genetic algorithm (GA), particle swarm optimization (PSO), and software tools based on the numerical methods are mostly adopted in these articles. The numerical methods depend on the first-order and second-order gradient information of objectives and constraints to find the optimal solutions. Several common numerical methods have been utilized to solve ADS planning problems, such as linear programming, nonlinear programming, dynamic programming (DP), and ordinal optimization (OO).

In [45], for the purpose of minimizing the cost of DGO and maximizing the profit of DGO, a bi-level non-liner planning model is proposed to determine sittings and sizes of DDGs in ADS. To deal with this problem, the planning model is turned into an equivalent single-level mixed-integer linear programming problem and it is solved by CPLEX. A mixed integer second-order cone a programming problem that is formulated to determine the allocation scheme of ESSs in [57]. GUROBI is adopted to solve this problem. Similar with [57], the same methods are adopted in [58] to solve the joint planning 
problem of substations, feeders, and RDGs in ADS. In [55], the allocation of EVs charging station is integrated into ADS planning model considering both charging and discharging behaviors of EVs, and the $\mathrm{OO}$ theory is adopted to solve this mixed-integer nonlinear programming problem. Different from [55], the mixed-integer nonlinear programming problem proposed in [36] is solved by DP.

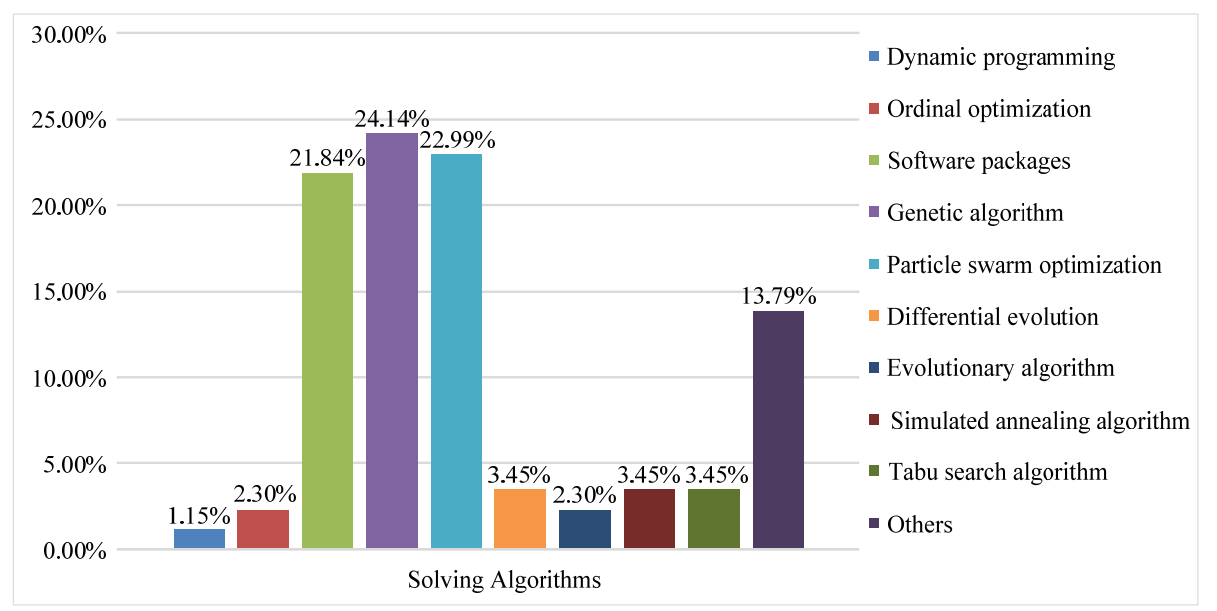

Figure 7. Distribution of solving algorithms.

In general, these classical numerical methods and the software tools based on these numerical methods (CONOPT [51,63,69], IPOPT [65,98], SNOPT [96], GUROBI [57,58,71,89], etc.) have been widely used to solve the ADS planning problem. However, due to the high-level uncertainties, these large-scale combinatorial optimization problems are easily to suffer from the "curse" of dimensionality. Therefore, it will take a large amount of computation time for solving these large-scale problems. In the meanwhile, some simplification actions for these planning models are required to be taken, which, in some extent, will result in the computational accuracy reduction of obtained planning results.

When comparing with these classic numerical methods, heuristic methods have the advantage to balance computational efficiency and accuracy. Nowadays, many kinds of heuristic methods have been widely served for power system optimization. GA, PSO, differential evolution (DE), and artificial bee colony algorithm $(\mathrm{ABC})$ are the successful examples to tackle the planning problems of ADS.

However, each of the heuristic algorithms has different strengths and weaknesses. GA has a good convergence property, but a drawback of complexity because of encoding and decoding. PSO s good at convergence speed, but easily trapped into the local optimum. DE needs less control parameters, and it has the advantage of better flexibility and the drawback of slow convergence speed. Therefore, the solution algorithm should be selected according to the features of different planning models. In addition, a hybrid algorithm based on different algorithms is also another good choice to enhance advantage and avoid disadvantage.

In [50], a modified PSO algorithm is developed by a new mutation operation and is adopted to solve a multi-objective multi-stage distribution expansion planning problem. The mutation operation is adopted to improve the global searching ability and to restrain the premature convergence to local optimal solution. In [38], the PSO algorithm is included in the shuffled frog leaping algorithm structure and implemented to cope with the optimization problem of the multi-stage ADS expansion planning problem. $A B C$ is adopted to solve a multi-stage expansion and unit commitment planning for ADSs in [43]. In the process of computational simulation, performances of the $\mathrm{ABC}$ algorithm are compared with the comprehensive learning PSO and the traditional multi-objective non-linear quadratic programming optimization method. The results indicate that $\mathrm{ABC}$ has a better convergence performance to solve the proposed planning model. 


\subsection{Case Study}

This section quotes a case study of ADS planning, introduced in [89], to illustrate the mathematic model and solving algorithm for ADS planning. The emphasis is also given to the comparison between traditional network reinforcement and the application of AM schemes.

To provide a reliable and cost effective service to consumers while ensuring that voltages and power quality are within standard ranges, minimizing the total cost serves as the optimization objective including (1) substations expansion cost; (2) new substations installation cost; (3) feeders' replacement cost; (4) new feeders installation cost; (5) installation cost of DG units; (6) operation cost of DG units; (7) cost of purchased energy; (8) system power loss cost; and, (9) AM schemes cost including DR incentive cost, and operation and maintenance (O\&M) cost of ESS.

There are four decision variables need to be determined in the planning scheme: (1) expansion capacity of existing substations; (2) sizes of existing substations for reinforcement; (3) locations and sizes of new feeders; and (4) locations and sizes of RDGs.

The constraints mainly consist of (1) the radiality constraint; (2) connection constraint; (3) power flow equations; (4) DG units' operating constraints; (5) DG units' maximum penetration constraint; (6) voltage constraint; (7) thermal limits of feeders and substations; (8) AM constraints and, (9) ESS operation constraints.

The 54-node, $33 \mathrm{kV}$ network is adopted to investigate the availability and effectiveness of the proposed model and the GUROBI solving tool. The planning schemes are given in Figure 8.

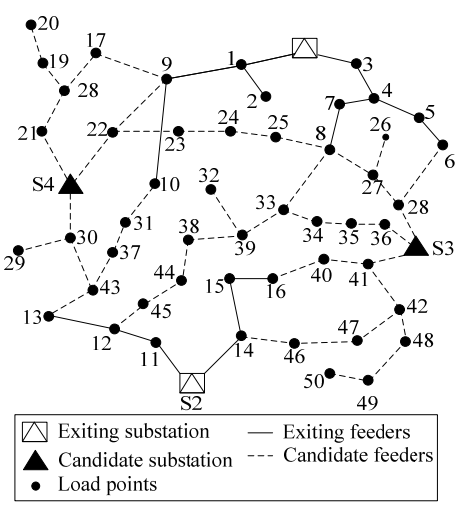

(a)

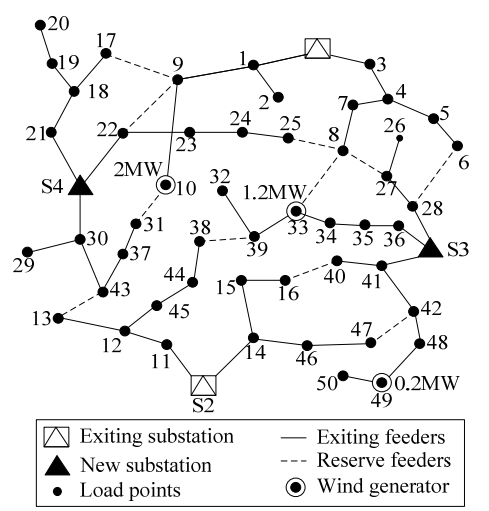

(b)

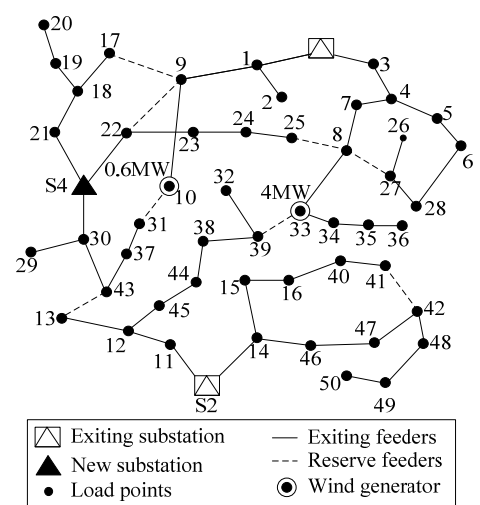

(c)

Figure 8. Case study based on 54-node distribution network (adapted from [89]). (a) Initial network;

(b) Expanded network without active managements (AMs); (c) Expanded network with AMs.

It can be observed that the main AM approaches adopted in this articles (operation of ESSs and DR) have a recommendable effect on upgrade deferral: the planning result considering these no-network solutions does not need to install substation S3 and corresponding feeders. As a result, the total cost decreases by $13.47 \%$. Meanwhile, the total penetration of DWG increases by $35.29 \%$ due to the implementation of these main AM approaches.

The case in [89] can illustrate the typical ADS planning models including objectives, decision variables, and constraints. The results also prove that the AM schemes should be properly considered in planning models and will bring several benefits for the planning solutions.

\section{Key Issues of ADS Planning}

\subsection{Methods to Deal with High-Level Uncertainties}

As aforementioned, more and more uncertainties will be faced in ADSs brought by changes in demand, generations, prices, and even policy. How to deal with these high-level uncertainties is a key 
problem that needs to be considered. At present, probabilistic approaches and multi-scenario based approaches are most common methods to cope with these multiple aspects of uncertainties.

1 Probabilistic approaches

When probabilistic approaches are used to deal with uncertainties, there is an assumption that the probability distribution function (PDF) of input parameters is known. As the main sources of uncertainties, wind speed, solar irradiance, and load demand, are approximately assumed to follow Weibull distribution, Beta distribution, and normal distribution, respectively, as shown from Equations (2)-(4). Therefore, these PDFs are adopted to represent the high fluctuation and randomness features of wind speed, solar irradiance, and load demand in many articles $[25,35,44,48,53,65,66,75,81,90]$.

$$
\begin{gathered}
f_{v}(v)=\left(\frac{k}{\lambda}\right)\left(\frac{v}{\lambda}\right)^{k-1} e^{-\left(\frac{v}{\lambda}\right)^{k}} \\
f(E)=\frac{\Gamma(\alpha+\beta)}{\Gamma(\alpha) \Gamma(\beta)}\left(\frac{E}{E_{\max }}\right)^{\alpha-1}\left(1-\frac{E}{E_{\max }}\right)^{\beta-1} \\
f_{\mathrm{L}}\left(P_{\mathrm{L}}\right)=\frac{1}{\sqrt{2 \pi} \sigma} \exp \left(\frac{\left(P_{\mathrm{L}}-\mu\right)^{2}}{2 \sigma^{2}}\right)
\end{gathered}
$$

where, $c$ and $k$ are scale parameter and shape parameter of Weibull distribution, respectively; $v$ is the wind speed at the height of the hub of wind turbine. $E$ is the sunlight intensity, $\alpha$ and $\beta$ are the shape coefficients of Beta distribution. $\Gamma$ is the Gamma function. $\mu$ and $\sigma$ are average value and standard deviation of load demand.

When the input parameters, such as $k, v, \alpha, \beta, \mu, \sigma$, are obtained, the required solar irradiance, wind speed, and load demand can be simulated by means of Monte Carlo Simulation, Latin Hypercube Sampling, etc. Then, the power outputs of DWG and DPV can be got by power output functions. The process is shown in Figure 9.
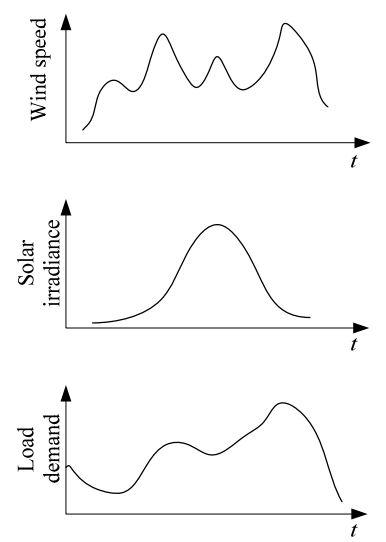

(a)
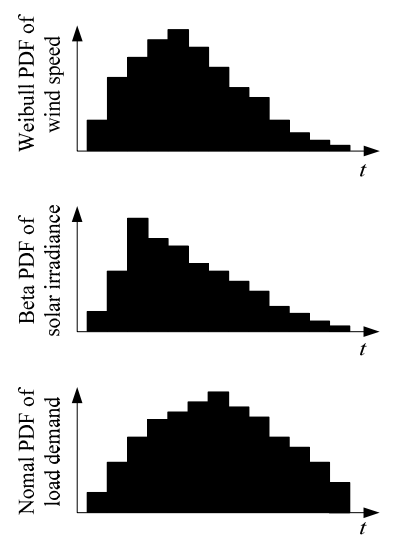

(b)
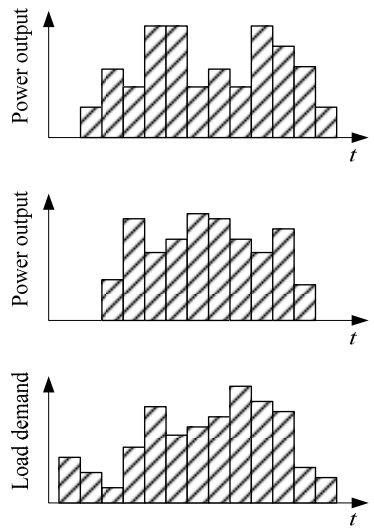

(c)

Figure 9. Simulation of power outputs and load demand based on probabilistic approaches.

(a) Prediction data; (b) probability distribution function (PDF); (c) Simulated data.

Then, combined with the approaches of probabilistic optimal power flow $[44,60,79]$, chance constrained programming [62,70], etc., these simulated data of RDGs and load demand could be used in ADS planning models considering high-level uncertainties.

Although, these probabilistic approaches have the ability to reflect the intermittent nature of DWG, DPV and load demand, they can not give full expression to the time-variable nature of these RDGs and load demand (e.g., autocorrelation). Therefore, using these approaches based on PDF 
may lead to the neglect of annually inherent simultaneity of multiple RDGs and load demand, and probably generating incorrect operation point combinations. At the same time, the seasonal/diurnal complementariness may escape from researchers' notice. In [53], although joint probability density functions are adopted to simulate these complementary features between DWG and load demand, the simulation results still need further improvement.

Moreover, due to the strict time sequential operation constraints of ESSs and DR, these probabilistic approaches, which can not capture the time-variable nature and represent the behaviors of AMs, are not suitable for ADS planning models coupled with operation of ESSs and DR.

\section{Multi-scenario based approaches}

In the approaches based on multi-scenario, a set number of typical scenarios are formed based on forecasting data to capture the combinations of different uncertainty factors, such as wind speed, solar irradiance, load demand, and market electricity prices. Then, these typical scenarios serve as the basic data to solve ADS planning models. Obviously, a large number of clusters will bring about more accurate planning solutions, but would be at the cost of a surge in scenario quantity and the burden of computation. Therefore, in order to balance computational efficiency and accuracy, scenario reduction is always adopted in many articles $[25,53,75]$.

In several articles, such as $[22,60,71,84,95]$, the fewer seasonal typical scenarios are adopted to represent the random fluctuations of RDGs and load demand. It is obvious that the computational burden is eased, but the computational accuracy of planning solutions is reduced at the same time.

A recommendable approach based on multi-scenario is adopted in several articles. In these papers, the annual time-dependent data are segmented into 365 daily intervals and are normalized. Then, these 365 daily intervals are created as a matrix that contains the 24 (h) of data of the load, solar irradiance, and wind speed. By means of fuzzy clustering algorithm [99] or K-means clustering algorithm $[57,58,75,89]$, the typical scenarios with similar characteristics are clustered.

The approach has the ability to keep the diversity of scenarios, while eases the computational burden. By this means, these typical daily scenarios can be extracted from these annual prediction data and assumed to be sufficiently representative of the sequential behaviors and inherent simultaneity between multiple RDGs and load demand. Therefore, it is one of recommendable approaches to handle high-level uncertain factors. However, in the process of clustering, the number of cluster is determined without deliberateness, and few of the abovementioned references take the quality and diversity of these selected typical daily scenarios into account adequately. In this regard, several property validity indices, such as Davies Bouldin index [113], Cluster cardinality index [114], and Xie \& Beni index [115], should be adopted to determine the proper number of typical daily scenarios with high quality and diversity. A simple numerical example is adopted to illustrate the process of scenario clustering based on Davies Bouldin index, shown as Figure 10.

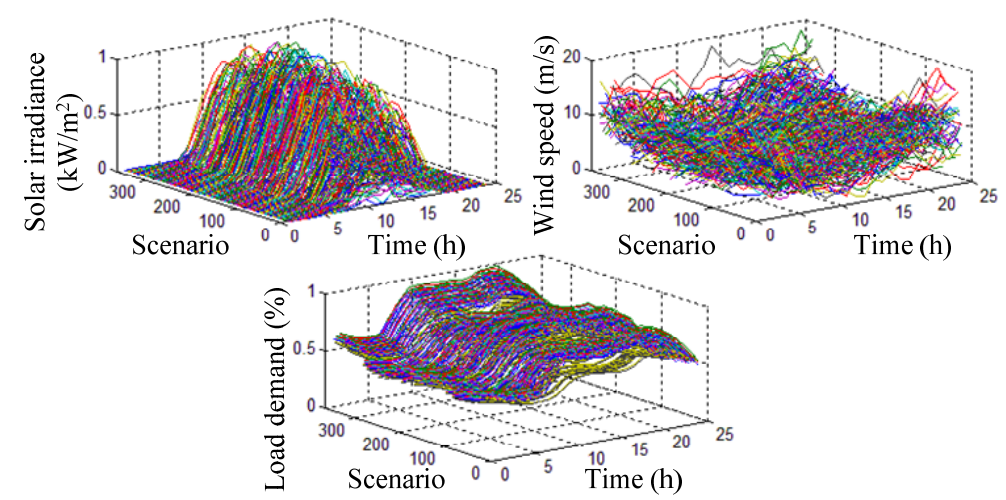

(a)

Figure 10. Cont. 

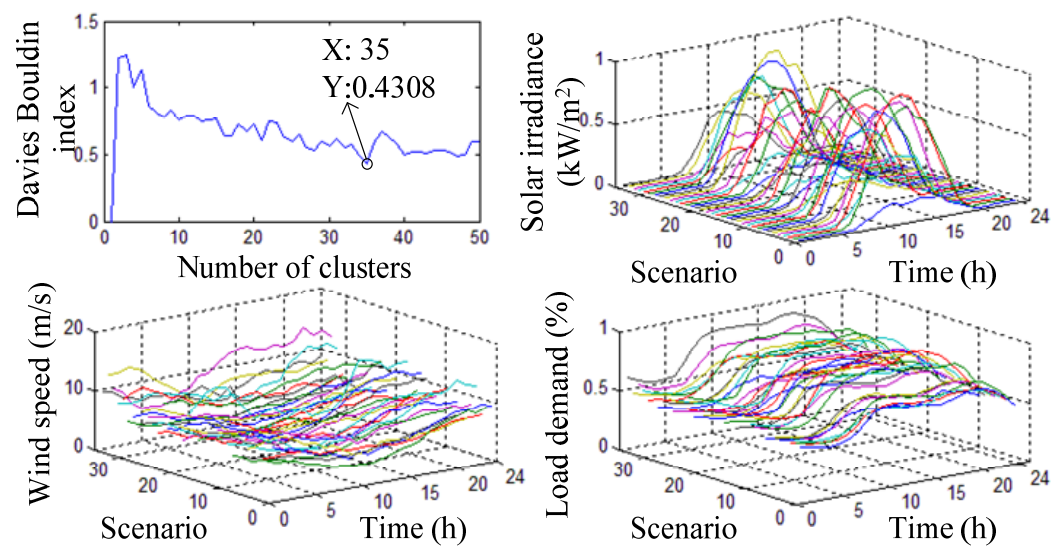

(b)

Figure 10. Simulation results by multi-scenario based approaches with Davies Bouldin index. (a) Annual time-dependent data; (b) Typical scenarios after clustering.

\subsection{Methods to Incorporate Operational Aspects into Planning Model}

When comparing with traditional distribution networks, the ability to control DERs by means of AM schemes is the most prominent feature of ADS. These AMs and control schemes, defined as no-network solutions, offer many potential benefits to the planning of ADSs and have become valuable alternatives to network expansion or reinforcement [10]. Therefore, the planning consideration and operation consideration should not be optimized separately any more.

In $[60,63,69,71]$, in order to optimize operation and planning of ADSs coordinately, the bi-level structure is introduced to formulate the ADS planning models and achieve the coordinate optimization between planning and operation, as shown in Equation (5).

$$
\begin{aligned}
& \min F\left(x_{s t}, y_{s t}, z_{s t, s c, t}\right)=\left[O F_{1}, O F_{2}, \ldots, O F_{M}\right] \\
& \text { s.t. }\left\{\begin{array}{l}
G\left(x_{s t}, y_{s t}\right)=0 \\
H\left(x_{s t}, y_{s t}\right) \leq 0 \\
1 \leq s t \leq N_{S T} \\
\text { where } z_{s t, s c, t} \text { should be solved from: } \\
\min f\left(x_{s t}, y_{s t}, z_{s t, s c, t}\right)=\left[o f_{1}, o f_{2}, \ldots, o f_{n}\right]
\end{array}\right. \\
& \text { s.t. }\left\{\begin{array}{l}
g\left(x_{s t}, y_{s t}, z_{s t, s c, t}\right)=0 \\
h\left(x_{s t}, y_{s t}, z_{s t, s c, t}\right) \leq 0 \\
1 \leq t \leq 24 \\
1<s c \leq N_{S C}
\end{array}\right.
\end{aligned}
$$

where, $x_{s t}, y_{s t}$ are the decision variables of planning of networks and allocations of DERs. $O F_{1}, O F_{2}, \ldots, O F_{M}$, are the optimal objectives of planning model. $G($.$) and H($.$) are the equality$ constraints and inequality constraints. $z_{s t, s c, t}$ is the decision variables of operation, which are solved in lower level models. of $f_{1}, o f_{2}, \ldots, o f_{n}$, are the optimal objectives of operation model in lower level. $g($.$) and h($.$) are the equality constraints and inequality constraints. s c$ and $t$ denotes the scenario $s c$ and time $t$, respectively. Moreover, $N_{\mathrm{ST}}$ is number of planning stage; when $N_{\mathrm{ST}}=1$, the planning model is a static planning model, otherwise the model is a dynamic multi-stage planning model.

The bi-level models adopted in these papers belong to the multi-level programming, which is first introduced to model the extension problem of the Stackelberg Games by Candler and Norton [116]. At present, the multi-level programming has become a hot topic in the optimization field research, and has been widely used for varieties fields of sciences, engineering, and economics. In a bi-level model, each level of the model has its objectives and decision spaces, which are affected by variables controlled at another level. That enables the optimization objectives and the interaction of different decision makers 
be taken into account. Meanwhile, the execution of decisions is sequential, from higher to lower level, which is consistent with the logical relationship between planning and operation. These features of bi-level model enable itself to be suitable for hybrid optimization of ADS planning and operation. The ADS planning structure based on bi-level programming is shown in Figure 11.

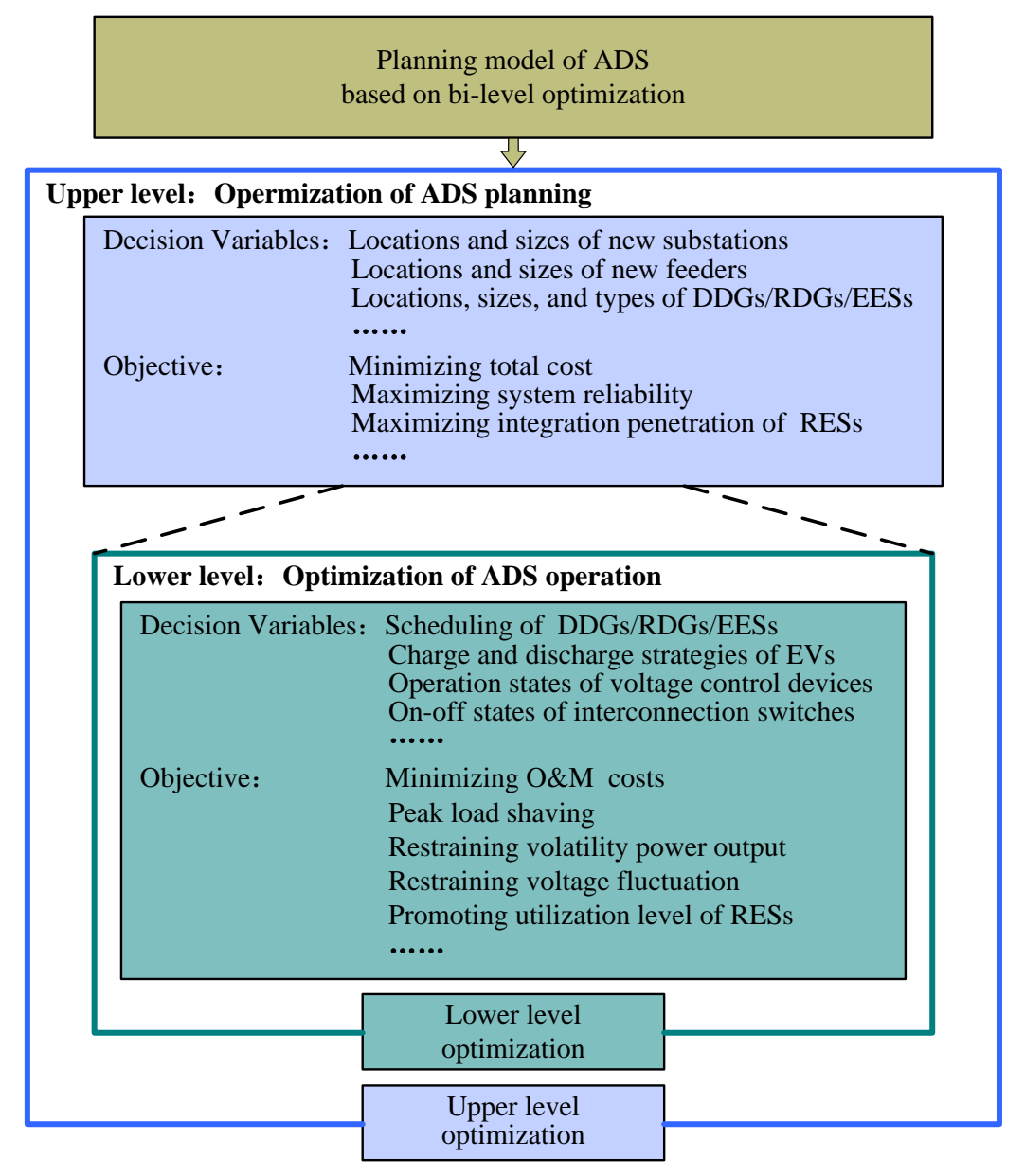

Figure 11. The active distribution systems (ADS) planning structure based on bi-level programming.

In this structure, the upper level model serves as a leader and plays a decisive role to determine the planning schemes of ADS. The lower level model serves as a follower and determines the operation conditions of ADS under the candidate planning scheme that is obtained by the upper level. At the same time, the evaluation indicators obtained by the lower level, such as operation costs, reliability indexes, and the utilization level of RDGs, will be fed back to the upper level and impact the optimal planning schemes. Finally, the optimal planning schemes can be obtained as well as the optimal operation situations, by the iterative optimization mentioned above.

Authors in [25] adopt the bi-level structure to solve an allocation problem of DGs, where capacities, types, and locations of DGs are obtained in the master optimization problem (upper level model), and the optimal active and reactive power outputs of DG units are determined in the sub-optimization problem (lower level model). Similar with [25], a bi-level model is adopted to formulate an allocation of DGs in [62]. But, the lower level model serves to examine the feasibility of candidate planning schemes by the voltage profiles and reliability performance.

A case study is adopted to illustrate the utilization of bi-level models in ADS planning. A bi-level optimization problem is proposed in [60] to model the planning of ESSs in ADS, where the planning problem and operation problem are optimized in the upper level and lower level, respectively. 
For the planning aspect, minimizing the total costs of the ADS and ESS serves as the objective of the upper level, including (1) minimization of the storage investment cost; (2) minimization of O\&M cost; (3) minimization of reliability cost; and, (4) minimization of the number of technical constraints' violations. For the operation aspect, ESS operation scheduling is obtained for three purposes simultaneously including peak shaving, voltage regulation, and reliability enhancement in the lower level. These roles of ESSs are modeled as operation costs, reliability costs, and the penalty factor, and are fed back to the upper level. To address this problem, PSO serves as the basic frame of the hybrid solving strategy to determine the allocation of ESS in the upper level. Tabu search serves as the algorithm embedded in the basic frame to obtain ESS scheduling in the lower level. The 21-node, $13.8 \mathrm{kV}$ network is adopted to investigate the availability and effectiveness of the proposed model and the hybrid solving strategy, shown as Figure 12. The planning results are given in Table 2, including the optimal locations, capacities, and power ratings of the ESSs in different wind penetration.

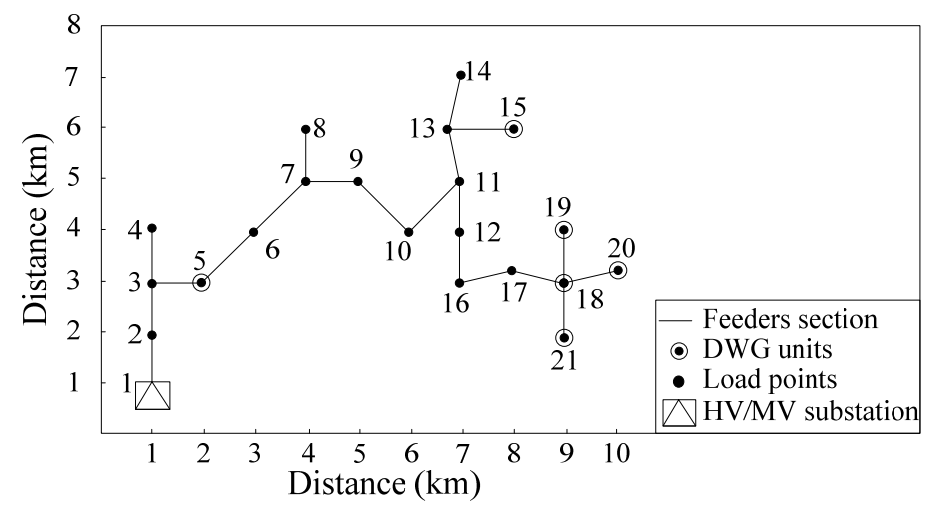

Figure 12. Case study based on 21-node distribution network (adapted from [60]).

Table 2. Different planning results for different distributed wind generations (DWG) penetration.

\begin{tabular}{lccccccc}
\hline \multirow{2}{*}{ DWG penetration $=0 \%$} & Location $($ Node No.) & 15 & 19 & 20 & 21 & - & Total \\
& Capacity $(\mathrm{kWh})$ & 590 & 80 & 630 & 630 & - & 1930 \\
& Power rating $(\mathrm{kW})$ & 120 & 45 & 125 & 120 & - & 410 \\
\hline \multirow{3}{*}{ DWG penetration $=10 \%$} & Location $($ Node No.) & 13 & 15 & 17 & 19 & 20 & Total \\
& Capacity $(\mathrm{kWh})$ & 780 & 770 & 800 & 715 & 710 & 3775 \\
& Power rating $(\mathrm{kW})$ & 150 & 170 & 150 & 150 & 160 & 780 \\
\hline \multirow{3}{*}{ DWG penetration $=30 \%$} & Location $($ Node No.) & 11 & 13 & 15 & 19 & 20 & Total \\
& Capacity $(\mathrm{kWh})$ & 1680 & 1880 & 1840 & 1820 & 1365 & 8585 \\
& Power rating $(\mathrm{kW})$ & 275 & 300 & 290 & 290 & 245 & 1400 \\
\hline
\end{tabular}

It can be observed that with the increase of DWG penetration, the required capacities of ESSs increase considerably, which reveals the improvement effect of ESS on the accommodation of fluctuate RDGs. It also can be found that these ESSs tend to be located far from the HV/MV substation to alleviate the challenge of higher power losses, voltage fluctuation, and outage probability [60]. In addition, the comparing of the cost items, including operation cost, reliability cost, penalty factor, and average power losses, also indicates that the utilization of ESS reduces all of these cost items separately, even if minimizing the total costs serves as the optimization objective.

Generally speaking, shown as the case study in [60], the bi-level optimization model enables us to take into account how optimal operation consideration of ADS in the lower level can affect and be affected by the optimal planning of ADS in the upper level, which has the ability to bring potential benefits from operational strategies to the planning studies. 


\subsection{Integration of ESSs and DR}

With the increasing application of ESSs and DR, the success of these programs makes ESSs and DR be perceived as virtual distributed resources. The benefits brought by operation of ESSs and DR have attracted researches' attention. However, most of these researches focus on the operational challenges rather than planning aspects [10]. Only $20 \%$ of the selected articles integrate optimal operation of ESSs into ADS planning, while less than $10 \%$ of the selected papers involve the performance of DR.

Authors in [32] integrate the allocation of ESSs into multi-stage distribution expansion planning model, where several operation strategies are proposed for DGs and ESSs operation to cut peak load demand and enhance system reliability. In [46], authors introduce a planning model to determine the allocation of customer-side ESS to deal with voltage fluctuation problem in ADS with high penetration of PV systems. A suitable connection agreement is adopted to allow the DSO to control the operation output of customer-side ESS during a specific time period in exchange for a subsidy, which can be used to reduce the initial cost of ESS. Similar with [32], a multi-stage distribution network expansion planning model is proposed incorporating ESSs in [67]. A straightforward operation strategy of ESSs is introduced to shave the peak demand and to reduce the planning cost. In [72], the optimal operation of ESSs and DGs is incorporated into the coordinated planning on the ESSs and DGs. It is noteworthy that both active power and reactive power of ESSs are adequately addressed and discussed, which is less common in other papers.

As the most representative dynamic active load demand, charging load demands of EVs have a major impact on ADS planning. Moreover, EVs also have the ability to discharge and participate energy management in ADS. Therefore, it is required to investigate the important impact of EVs on optimal planning of ADS.

In [83], a fuzzy load model of EVs is adopted to investigate the impacts of EVs' uncertainties on ADS planning. Optimal allocation of EESs and DDGs serves as the solution to deal with the undesirable impacts mentioned above. But optimal charging and discharging strategies of EVs are not involved in this paper. Authors in [99] propose an ADS expansion planning model to support increasing penetrations of EVs, where the uncertainties and charging behaviors of EVs are taken into consideration. The results indicate that the ordered charging behaviors of EVs can reduce the investment and operation costs of ADS, and have noteworthy beneficial effects on ADS planning.

Different from these two references, the allocation of EVs charging station is integrated into ADS planning model in $[54,55,80,82,85]$. Among them, authors in $[54,80,82,85]$ introduce the traffic flow index into the proposed planning models to present the convenience of charging service. By means of the proposed models, the ADS and transportation systems are optimized collaboratively.

Besides of EVs, other flexible load demands can also be considered as virtual DERs to participate energy management in ADS by means of time-based programs, incentive-based programs, and market-based programs [84]. The success of DR programs is beneficial to improving the utilization of RDGs [48,81], reducing the operation costs [81,89] and energy losses [89], decreasing load peak and off-peak difference, and mitigating the mismatch between load demand and outputs of RDGs.

Authors in [48] propose an integrated ADS planning model to optimize reinforcement scheme of networks and allocation of DGs. In the process, a truncated Gaussian distribution is applied to represent the elasticity variations of price responsiveness in DR programs. What is noteworthy is that the smart metering devices are taken into consideration in the ADS planning methodology. In $[81,84,89,96]$, DR serves as an AM scheme integrated into ADS planning model. Among them, authors in [81] adopt the flexible load as a kind of virtual energy storage unit with bi-directional power output to reduce the operation costs. In [84], DR programs are integrated in a multi-level and multi-objective ADS expansion planning model, where DR specifications are optimized by means of sensitivity analysis in lower level and feedback to other level, so that the optimal DR programs can be taken into account in ADS planning modes effectively.

Many of the references select simple models to represent the optimal operation of ESSs, DR programs, and EVs. However, these AM schemes, especially ESSs, have the strict operational constraints and flexible 
operational strategies, which cannot be captured and represented by simple models. Therefore, further studies are needed about the operational models integrated into planning models.

\subsection{Methods to Deal with Multiple Time Scales}

As mentioned above, the co-optimization between planning in long-time scale and operation in short-time scale is a key issue for ADS planning models. This requires the definition of adequate time-series models to be able to adequately represent the behaviors of active approaches in the planning calculations $[10,20]$. Therefore, the coordination of multiple time scales is an important problem to determine what extent operational aspects need to be modelled in planning models.

In terms of planning consideration, there are three kinds of ADS planning problems including long-term planning, median-term planning, and short-term planning. Correspondingly, the planning horizons of them are 16-30 years [35,41,52,64], 6-15 years [34,42,59,61,71,96,97], and 1-5 years $[31,38,43,67,84,86]$, respectively. In most of the articles, capital recovery factor is adopted to calculate the net present value of equal annual cash flows and economic objectives. Moreover, discounted payback period and benefit-cost ratio also can be taken into consideration [92].

In terms of operation consideration, the time scales are closely associated with the different response time of AM schemes, such as seconds, or minutes, and hours [69]. Taking the operation of ESSs as an example, super-capacitor and battery normally have different response rates, therefore they play different roles in ADS operation.

There is no doubt that the fine granularities have a better ability to capture operation situations. But in the process of planning models, the simplistic representations in hour interval will barely affect the quality of planning solutions and have the ability to ease the calculating burden $[10,20]$. Therefore, it is widely accepted to take one hour as the elementary interval in the planning calculations.

Moreover, because of the daily cycling operation of ESSs, DR programs, and EVs, the time scales of planning and operation can be united by diurnal evaluation criteria based on the probabilistic multi-scenario, such as diurnal investment and operation costs, and the diurnal reliability index. The expectation values of these criteria calculated by multiple scenarios and corresponding probabilities can be adopted to iterative optimization, shown as Figure 13.

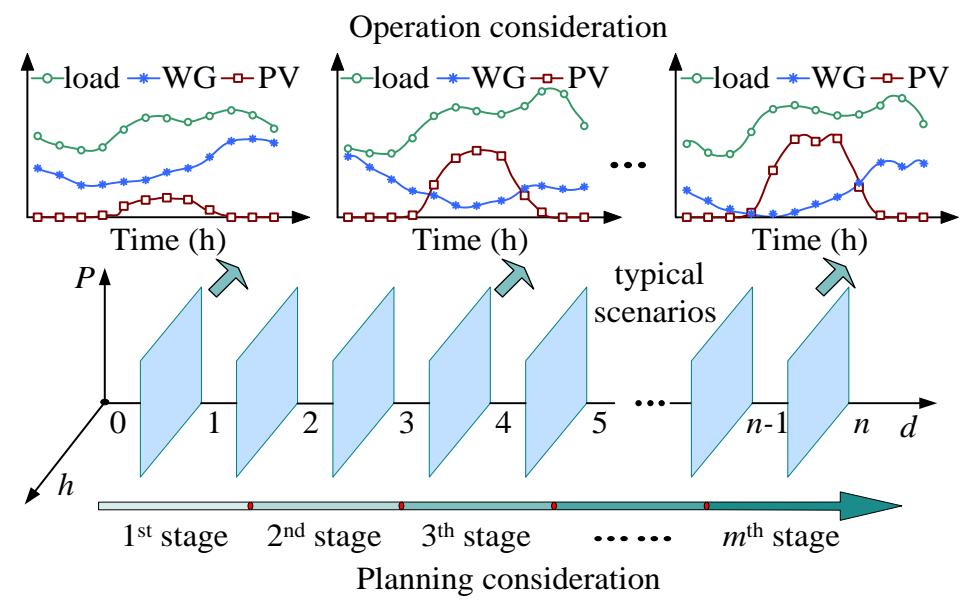

Figure 13. Methods to deal with multiple time scales by multiple scenarios.

\section{Recommendation for Future Works of ADS Planning}

\subsection{ADS Planning with Multiple Micro-Grids}

MGs have the ability to aggregate many DERs, such as DGs and distributed energy devices, and operate as a controlled and efficient energy unit for economic and reliability purposes by fast acting power electronics. Furthermore, MGs also can improve the utilization of RDGs and take some degree 
of responsibility to support ADS [117]. Therefore, more and more RDGs are prone to be integrated by means of MGs. So that a new pattern that can be referred as multi-MGs has emerged in ADS, shown as Figure 14. In this architecture, the goal of global coordination in ADS and regional autonomy in MGs can be achieved [118-120].

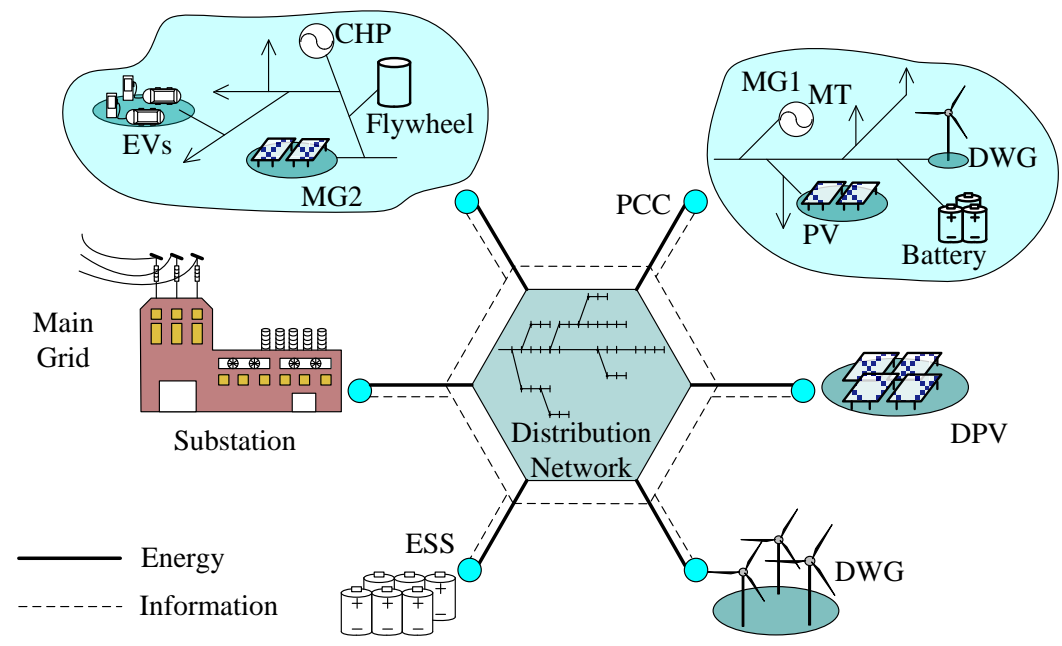

Figure 14. ADS architecture with multi-MGs.

At present, ADSs with multi-MGs have been studied in some literature. However, most existing literature are directed towards the operation issues but not planning problems [118-122]. Even though there has been a small part of literature that spends efforts on the planning of ADS with multi-MGs, there are many problems that remain unsolved $[117,123]$. First of all, it requires rethinking ADS planning models with appropriate optimization objectives to satisfy the different planning goals of stakeholders. Secondly, more uncertain factors need to be handled in the planning process, such as various operation states combined with different islanding/connecting operation of multi-MGs. Moreover, how to integrate control strategies of multi-MGs into ADS planning is another important issue to be considered.

Therefore, ADS planning with multi-MGs is a valuable and recommendable topic that needs to be further researched.

\subsection{Collaborative Planning Methods of ADS and Information Communication System}

In ADSs, the real-time energy optimization and coordinative AMs between a mass of DERs and multi-MGs bring great challenges on the information and communication technologies (ICT). The reliability of ICS directly impacts the observability and the controllability of ADS, which is the firm foundation for the secure and stable operation of ADS [124-127]. Therefore, the allocation of ICS devices and planning of ADS should no longer to be optimized as separate tasks. The collaborative planning of ADS and ICS is another recommendable topic that needs to be further researched.

To realize situational awareness and autonomous decision-making of DERs, ICS components should be allocated according to the management strategies and physical architecture of ADS. Only in this way, can the massive, distributed and heterogeneous data resources be captured, transmitted, processed, and utilized.

In the collaborative planning, the co-simulation approaches of ADS and ICS need to be further studied to simulate power delivery and communications networks simultaneously. In terms of economic assessment, the investment and operation costs of ICS components should be integrated into the economic objectives. More importantly, in terms of reliability assessment, the potential impacts of ICS operation quality (e.g., accuracy, security, availability, performance) on ADS reliability should be evaluated accurately and taken into account adequately. 


\subsection{ADS Planning from Different Perspectives of Multi-Stakeholders}

With the liberalization of electricity markets, many new stakeholders have emerged to participate the market operation. More and more DDGs, RDGs, and EESs are invested by the independent DGOs instead of DSOs. This is the typical scenario in Ontario, Canada and Sacramento Municipal Utility District in California, USA [33,35]. These DGOs would like to take part in market competition and realize the profits by means of selling electricity to the grid and the arbitrage by ESSs.

Therefore, the different and even conflicting planning goals of system stakeholders should be taken into account, shown as Table 3 . However, except for $[33,35,45,46,71,81,84]$, the other papers all lose sight of this problem and assume that DGs all belong to DSOs. It means that the liberalization of the electricity market environment has not been adequately taken into consideration.

Table 3. Different planning goals of distribution system operators (DSOs) and distributed generation operators (DGOs) [10].

\begin{tabular}{ll}
\hline & \multicolumn{1}{c}{ Planning Goals } \\
\hline \multirow{3}{*}{ DSOs } & $\begin{array}{l}\text { Increased customer services (e.g., being able to connect generation customers and demand } \\
\text { customers more quickly and cost effectively) }\end{array}$ \\
\cline { 2 - 2 } & Better system performance metrics (e.g., reliability and electric power quality) \\
\cline { 2 - 2 } & Reducing the investment, maintenance, and operation costs \\
\cline { 2 - 2 } & Quicker and cheap connections \\
\hline \multirow{2}{*}{ DGOs } & Investment incentives \\
\cline { 2 - 2 } & $\ldots . .$. \\
\hline
\end{tabular}

Hejazi et al. [33] are the early scholars to plan ADS from the different perspectives of stakeholders, where maximizing the DSO's profit is adopted to be the objectives, while maintaining positive profit for each independent DGOs serves as a constraint condition to assure DG investment attractive. In [45], the game relationship between DGOs and DSOs is modeled appropriately by a bi-level programming. The minimizing investment and operation costs of DSOs and maximizing the profit value of DGOs are adopted to be the objectives of the upper level and lower level, respectively. The contract prices of DGs between DGOs and DSOs are optimized together with the allocation of DDGs. From the different perspectives of stakeholders, authors in $[81,84]$ use the multi-level programing to determine the optimal reinforcement schemes of ADS and allocation of DGs under the condition of a competitive market environment.

Judging based on the present condition; further study may be still needed to find optimal compromise planning solutions for the conflicting objectives of different stakeholders.

\section{Conclusions}

This paper presents a timely overview of ADS planning models and methodologies from different perspectives. The key issues and research prospects in the field of ADS planning methods are analyzed and discussed with several remarkable conclusions.

1. The environmental issues and allocation of reserve feeders, voltage control devices, and dynamic active load demand are deserving of more attention from the perspectives of optimization objective and decision variable, respectively.

2. Probabilistic multi-scenario based approaches and the multi-level programming are recommendable approaches to handle the key issues related with high-level uncertainties, the incorporating operational aspects into planning model, the integration of ESSs and DR, and the methods to deal with multiple time scales. 
3. ADS planning with multi-MGs, collaborative planning methods between ADS and ICS, and ADS planning from different perspectives of multi-stakeholders are the valuable and recommendable topics that need to be further researched.

Acknowledgments: This project was supported by The National Key Research and Development Program of China (2016YFB0900500).

Author Contributions: All authors contributed in equal parts to the paper, whereby Rui Li was responsible for writing the initial manuscript. Wei Wang, Zhe Chen, Jiuchun Jiang, and Weige Zhang were mainly responsible for organizing and revising the whole paper.

Conflicts of Interest: The authors declare no conflict of interest.

\section{Abbreviations}

\begin{tabular}{|c|c|}
\hline $\mathrm{ABC}$ & Artificial Bee Colony \\
\hline $\mathrm{ADN}$ & Active Distribution Network \\
\hline ADS & Active Distribution System \\
\hline $\mathrm{AM}$ & Active Management \\
\hline $\mathrm{CHP}$ & Combined Heat and Power \\
\hline DDG & Dispatchable Distributed Generations \\
\hline $\mathrm{DE}$ & Differential Evolution \\
\hline DER & Distributed Energy Resource \\
\hline DG & Distributed Generation \\
\hline DGO & Distributed Generation Operator \\
\hline DP & Dynamic Programming \\
\hline DR & Demand Response \\
\hline DSO & Distribution System Operator \\
\hline DPV & Distributed Photovoltaic \\
\hline DWG & Distributed Wind Generation \\
\hline $\mathrm{EV}$ & Electric Vehicle \\
\hline ESS & Energy Storage System \\
\hline GA & Genetic Algorithm \\
\hline MG & Micro-Grid \\
\hline MT & Micro Turbine \\
\hline OLTC & On-load Tap Changer \\
\hline $\mathrm{OO}$ & Ordinal Optimization \\
\hline O\&M & Operation and Maintenance \\
\hline PCC & Point of Common Coupling \\
\hline PDF & Probability Distribution Function \\
\hline RDG & Renewable Distributed Generation \\
\hline RES & Renewable Energy Source \\
\hline PSO & Particle Swarm Optimization \\
\hline SVC & Static Var Compensator \\
\hline ICS & Information Communication System \\
\hline ICT & Information Communication Technology \\
\hline
\end{tabular}

\section{References}

1. Kroposki, B.; Johnson, B.B.; Zhang, Y.C.; Gevorgian, V.; Denholm, P.; Hodge, B.-M.S.; Hannegan, B. Achieving a $100 \%$ renewable grid: Operating electric power systems with extremely high-levels of variable renewable energy. IEEE Power Energy Mag. 2017, 15, 61-73. [CrossRef]

2. You, S.; Lin, J.; Hu, J. The Danish perspective of energy internet: From service-oriented flexibility trading to integrated design, planning and operation of multiple cross-sectoral energy systems. Proc. CSEE 2015, $35,3470-3481$.

3. Philibert, C.; Frankl, P.; Tam, C.; Abdelilah, Y.; Bahar, H.; Marchais, Q.; Wiesner, H. Technology Roadmap Solar Photovoltaic Energy; International Energy Agency: Paris, France, 2014. 
4. Omu, A.; Choudhary, R.; Boies, A. Distributed energy resource system optimisation using mixed integer linear programming. Energy Policy 2013, 61, 249-266. [CrossRef]

5. Hu, Z.; Li, F. Cost-benefit analyses of active distribution network management, part I: Annual benefit analysis. IEEE Trans. Smart Grid 2012, 3, 1067-1074. [CrossRef]

6. Hu, Z.; Li, F. Cost-benefit analyses of active distribution network management, part II: Investment reduction analysis. IEEE Trans. Smart Grid 2012, 3, 1075-1081. [CrossRef]

7. Zhang, J.; Cheng, H.; Wang, C. Technical and economic impacts of active management on distribution network. Int. J. Electr. Power Energy Syst. 2009, 31, 130-138. [CrossRef]

8. Abapour, S.; Zare, K.; Mohammadi-Ivatloo, B. Evaluation of technical risks in distribution network along with distributed generation based on active management. IET Gener. Transm. Distrib. 2014, 8, 609-618. [CrossRef]

9. Christian, D.A.; Taylor, P.C.; Jupe, S.; Buchholz, B.; Pilo, F.; Abbey, C.; Marti, J. Active distribution networks: General features, present status of implementation and operational practices. Electra 2009, 246, 22-29.

10. Planning and Optimization Methods for Active Distribution Systems Working Group C6.19. August 2014. Available online: https://www.researchgate.net/profile/Birgitte_Bak-Jensen/publication/283569552_ Planning_and_optimization_methods_for_active_distribution_systems/links/566e7ebc08ae430ab50027b9/ Planning-and-optimization-methods-for-active-distribution-systems.pdf (accessed on 25 October 2017).

11. D'Adamo, C.; Jupe, S.; Abbey, C. Global survey on planning and operation of active distribution networks: Update of CIGRE C6.11 working group activities. In Proceedings of the 20th International Conference and Exhibition on Electricity Distribution, Prague, Czech Republic, 8-11 June 2009; pp. 1-4.

12. Hidalgo, R.; Abbey, C.; Joós, G. A review of active distribution networks enabling technologies. In Proceedings of the IEEE Power and Energy Society General Meeting, Minneapolis, MN, USA, 25-29 July 2010; pp. 1-9.

13. Kazmi, S.A.A.; Shahzad, M.K.; Khan, A.Z.; Shin, D.R. Smart distribution networks: A review of modern distribution concepts from a planning perspective. Energies 2017, 10, 501. [CrossRef]

14. Xiang, Y.; Liu, J.; Li, F.; Liu, Y.; Liu, Y.; Xu, R.; Su, Y.; Ding, L. Optimal active distribution network planning: A review. Electr. Power Compon. Syst. 2016, 44, 1075-1094. [CrossRef]

15. Georgilakis, P.S.; Hatziargyriou, N.D. A review of power distribution planning in the modern power systems era: Models, methods and future research. Electr. Power Syst. Res. 2015, 121, 89-100. [CrossRef]

16. Kazmi, S.; Shahzad, M.; Shin, D. Multi-objective planning techniques in distribution networks: A composite review. Energies 2017, 10, 208. [CrossRef]

17. Huda, A.S.N.; Živanović, R. Large-scale integration of distributed generation into distribution networks: Study objectives, review of models and computational tools. Renew. Sustain. Energy Rev. 2017, 76, 974-988. [CrossRef]

18. Jain, S.; Kalambe, S.; Agnihotri, G.; Mishra, A. Distributed generation deployment: State-of-the-art of distribution system planning in sustainable era. Renew. Sustain. Energy Rev. 2017, 77, 363-385. [CrossRef]

19. Saboori, H.; Hemmati, R.; Ghiasi, S.M.S.; Dehghan, S. Energy storage planning in electric power distribution networks-A state-of-the-art review. Renew. Sustain. Energy Rev. 2017, 79, 1108-1121. [CrossRef]

20. Pilo, F.; Celli, G.; Ghiani, E.; Soma, G.G. New electricity distribution network planning approaches for integrating renewable. Wires Energy Environ. 2013, 2, 140-157. [CrossRef]

21. Hu, Z.; Li, F. Distribution network reinforcement utilizing active management means. In Proceedings of the IEEE Power and Energy Society General Meeting, Minneapolis, MN, USA, 25-29 July 2010; pp. 1-3.

22. Siano, P.; Chen, P.; Chen, Z.; Piccolo, A. Evaluating maximum wind energy exploitation in active distribution networks. IET Gener. Transm. Distrib. 2010, 4, 598-608. [CrossRef]

23. Martins, V.F.; Borges, C.L.T. Active distribution network integrated planning incorporating distributed generation and load response uncertainties. IEEE Trans. Power Syst. 2011, 26, 2164-2172. [CrossRef]

24. Falaghi, H.; Singh, C.; Haghifam, M.R.; Ramezani, M. DG integrated multi-stage distribution system expansion planning. Int. J. Electr. Power Energy Syst. 2011, 33, 1489-1497. [CrossRef]

25. Zou, K.; Agalgaonkar, A.P.; Muttaqi, K.M.; Perera, S. Distribution system planning with incorporating DG reactive capability and system uncertainties. IEEE Trans. Sustain. Energy 2011, 3, 112-123. [CrossRef]

26. Ganguly, S.; Sahoo, N.C.; Das, D. Mono-and multi-objective planning of electrical distribution networks using particle swarm optimization. Appl. Soft Comput. 2011, 11, 2391-2405. [CrossRef] 
27. Naderi, E.; Seifi, H.; Sepasian, M.S. A dynamic approach for distribution system planning considering distributed generation. IEEE Trans. Power Deliv. 2012, 27, 1313-1322. [CrossRef]

28. Sahoo, N.C.; Ganguly, S.; Das, D. Fuzzy-Pareto-dominance driven possibilistic model based planning of electrical distribution systems using multi-objective particle swarm optimization. Expert Syst. Appl. 2012, 39, 881-893. [CrossRef]

29. Sahoo, N.C.; Ganguly, S.; Das, D. Multi-objective planning of electrical distribution systems incorporating sectionalizing switches and tie-lines using particle swarm optimization. Swarm Evol. Comput. 2012, 3, 15-32. [CrossRef]

30. Millar, R.J.; Kazemi, S.; Lehtonen, M.; Saarijarvi, E. Impact of MV connected microgrids on mv distribution planning. IEEE Trans. Smart Grid 2012, 3, 2100-2108. [CrossRef]

31. Borges, C.L.T.; Martins, V.F. Multi-stage expansion planning for active distribution networks under demand and distributed generation uncertainties. Int. J. Electr. Power Energy Syst. 2012, 36, 107-116. [CrossRef]

32. Sedghi, M.; Aliakbar-Golkar, M.; Haghifam, M.R. Distribution network expansion considering distributed generation and storage units using modified PSO algorithm. Int. J. Electr. Power Energy Syst. 2013, 52, 221-230. [CrossRef]

33. Hejazi, H.A.; Araghi, A.R.; Vahidi, B.; Hosseinian, S.H. Independent distributed generation planning to profit both utility and DG investors. IEEE Trans. Power Syst. 2013, 28, 1170-1178. [CrossRef]

34. Samper, M.E.; Vargas, A. Investment decisions in distribution networks under uncertainties with distributed generation-part I: Model formulation. IEEE Trans. Power Syst. 2013, 28, 2331-2340. [CrossRef]

35. Zidan, A.; Shaaban, M.F.; El-Saadany, E.F. Long-term multi-objective distribution network planning by DG allocation and feeders' reconfiguration. Electr. Power Syst. Res. 2013, 105, 95-104. [CrossRef]

36. Sahoo, N.C.; Ganguly, S.; Das, D. Multi-objective planning of electrical distribution systems using; dynamic programming. Int. J. Electr. Power Energy Syst. 2013, 46, 65-78.

37. Junior, B.R.P.; Cossi, A.M.; Mantovani, J.R.S. Multiobjective short-term planning of electric power distribution systems using NSGA-II. J. Control Autom. Electr. Syst. 2013, 24, 286-299. [CrossRef]

38. Gitizadeh, M.; Vahed, A.A.; Aghaei, J. Multi-stage distribution system expansion planning considering distributed generation using hybrid evolutionary algorithms. Appl. Energy 2013, 101, 655-666. [CrossRef]

39. Chen, T.H.; Lin, E.H.; Yang, N.C.; Hsieh, T.Y. Multi-objective optimization for upgrading primary feeders with distributed generators from normally closed loop to mesh arrangement. Int. J. Electr. Power Energy Syst. 2013, 45, 413-419. [CrossRef]

40. Rosseti, G.J.S.; Oliveira, E.J.D.; Oliveira, L.W.D.; Silva, I.C.; Peres, W. Optimal allocation of distributed generation with reconfiguration in electric distribution systems. Electr. Power Syst. Res. 2013, 103, 178-183. [CrossRef]

41. Ziari, I.; Ledwich, G.; Ghosh, A.; Platt, G. Optimal distribution network reinforcement considering load growth, line loss, and reliability. IEEE Trans. Power Syst. 2013, 28, 587-597. [CrossRef]

42. Humayd, A.S.B.; Bhattacharya, K. Comprehensive multi-year distribution system planning using back-propagation approach. IET Gener. Transm. Distrib. 2013, 7, 1415-1425. [CrossRef]

43. El-Zonkoly, A.M. Multi-stage expansion planning for distribution networks including unit commitment. IET Gener. Transm. Distrib. 2013, 7, 766-778. [CrossRef]

44. Zhang, J.; Fan, H.; Tang, W.; Wang, M.; Cheng, H.; Yao, L. Planning for distributed wind generation under active management mode. Int. J. Electr. Power Energy Syst. 2013, 47, 140-146. [CrossRef]

45. Rider, M.J.; Lopez-Lezama, J.M.; Contreras, J.; Padilha-Feltrin, A. Bilevel approach for optimal location and contract pricing of distributed generation in radial distribution systems using mixed-integer linear programming. IET Gener. Transm. Distrib. 2013, 7, 724-734. [CrossRef]

46. Sugihara, H.; Yokoyama, K.; Saeki, O.; Tsuji, K.; Funaki, T. Economic and efficient voltage management using customer-owned energy storage systems in a distribution network with high penetration of photovoltaic systems. IEEE Trans. Power Syst. 2013, 28, 102-111. [CrossRef]

47. Liu, Z.; Wen, F.; Ledwich, G. Optimal planning of electric-vehicle charging stations in distribution systems. IEEE Trans. Power Deliv. 2013, 28, 102-110. [CrossRef]

48. Zeng, B.; Zhang, J.; Yang, X.; Wang, J.; Dong, J.; Zhang, Y. Integrated planning for transition to low-carbon distribution system with renewable energy generation and demand response. IEEE Trans. Power Syst. 2014, 29, 1153-1165. [CrossRef] 
49. Popović, Ž.N.; Kerleta, V.D.; Popović, D.S. Hybrid simulated annealing and mixed integer linear programming algorithm for optimal planning of radial distribution networks with distributed generation. Electr. Power Syst. Res. 2014, 108, 211-222. [CrossRef]

50. Aghaei, J.; Muttaqi, K.M.; Azizivahed, A.; Gitizadeh, M. Distribution expansion planning considering reliability and security of energy using modified PSO (particle swarm optimization) algorithm. Energy 2014, 65, 398-411. [CrossRef]

51. Kaabi, S.S.A.; Zeineldin, H.H.; Khadkikar, V. Planning active distribution networks considering multi-DG configurations. IEEE Trans. Power Syst. 2014, 29, 785-793. [CrossRef]

52. Mohtashami, S.; Pudjianto, D.; Strbac, G. Strategic distribution network planning with smart grid technologies. IEEE Trans. Smart Grid 2017, 8, 2656-2664. [CrossRef]

53. Zeng, B.; Zhang, J.; Zhang, Y.; Yang, X.; Dong, J.; Liu, W. Active distribution system planning for low-carbon objective using cuckoo search algorithm. J. Electr. Eng. Technol. 2014, 9, 433-440. [CrossRef]

54. Yao, W.; Zhao, J.; Wen, F.; Dong, Z.; Xue, Y.; Xu, Y. A multi-objective collaborative planning strategy for integrated power distribution and electric vehicle charging systems. IEEE Trans. Power Syst. 2014, 29, 1811-1821. [CrossRef]

55. Lin, X.; Sun, J.; Ai, S.; Xiong, X.; Wan, Y.; Yang, D. Distribution network planning integrating charging stations of electric vehicle with V2G. Int. J. Electr. Power Energy Syst. 2014, 63, 507-512. [CrossRef]

56. Kumar, D.; Samantaray, S.R.; Joos, G. A reliability assessment based graph theoretical approach for feeder routing in power distribution networks including distributed generations. Int. J. Electr. Power Energy Syst. 2014, 57, 11-30. [CrossRef]

57. Nick, M.; Cherkaoui, R.; Paolone, M. Optimal allocation of dispersed energy storage systems in active distribution networks for energy balance and grid support. IEEE Trans. Power Syst. 2014, 29, 2300-2310. [CrossRef]

58. Xing, H.; Cheng, H.; Zhang, L.; Zhang, S.; Zhang, Y. Second-Order Cone model for Active Distribution Network Expansion Planning. In Proceedings of the IEEE Power and Energy Society General Meeting, Denver, CO, USA, 26-30 July 2015; pp. 1-5.

59. Koutsoukis, N.C.; Georgilakis, P.S.; Hatziargyriou, N.D. Multi-stage power distribution planning to accommodate high wind generation capacity. In Proceedings of the IEEE Eindhoven PowerTech, Eindhoven, The Netherlands, 29 June-2 July 2015; pp. 1-6.

60. Sedghi, M.; Ahmadian, A.; Aliakbar-Golkar, M. Optimal storage planning in active distribution network considering uncertainties of wind power distributed generation. IEEE Trans. Power Syst. 2015, 31, 304-316. [CrossRef]

61. Abapour, S.; Zare, K.; Mohammadi-Ivatloo, B. Dynamic planning of distributed generation units in active distribution network. IET Gener. Transm. Distrib. 2015, 9, 1455-1463. [CrossRef]

62. Xu, X.; Makram, E.; Wang, T.; Medeiros, R. Customer-oriented planning of distributed generations in an active distribution system. In Proceedings of the IEEE Power and Energy Society General Meeting, Denver, CO, USA, 26-30 July 2015; pp. 1-5.

63. Dias, F.M.; Canizes, B.; Khodr, H.; Cordeiro, M. Distribution networks planning using decomposition optimisation technique. IET Gener. Transm. Distrib. 2015, 9, 1409-1420. [CrossRef]

64. Montoya-Bueno, S.; Muoz, J.I.; Contreras, J. A stochastic investment model for renewable generation in distribution systems. IEEE Trans. Sustain. Energy 2015, 6, 1466-1474. [CrossRef]

65. Mokryani, G. Active distribution networks planning with integration of demand response. Solar Energy 2015, 122, 1362-1370. [CrossRef]

66. Bagheri, A.; Monsef, H.; Lesani, H. Integrated distribution network expansion planning incorporating distributed generation considering uncertainties, reliability, and operational conditions. Int. J. Electr. Power Energy Syst. 2015, 73, 56-70. [CrossRef]

67. Saboori, H.; Hemmati, R.; Abbasi, V. Multi-stage distribution network expansion planning considering the emerging energy storage systems. Energy Convers. Manag. 2015, 105, 938-945. [CrossRef]

68. Liu, W.; Xu, H.; Niu, S.; Xie, J. Optimal Distributed Generator Allocation Method Considering Voltage Control Cost. Sustainability 2016, 8, 193. [CrossRef]

69. Alnaser, S.W.; Ochoa, L.F. Optimal sizing and control of energy storage in wind power-rich distribution networks. IEEE Trans. Power Syst. 2016, 31, 2004-2013. [CrossRef] 
70. Hejazi, H.; Mohsenian-Rad, H. Energy storage planning in active distribution grids: A chance-constrained optimization with non-parametric probability functions. IEEE Trans. Smart Grid 2016, 99, 1-13. [CrossRef]

71. Shen, X.; Shahidehpour, M.; Han, Y.; Zhu, S.; Zheng, J. Expansion planning of active distribution networks with centralized and distributed energy storage systems. IEEE Trans. Sustain. Energy 2016, 8, 126-134. [CrossRef]

72. Saboori, H.; Hemmati, R. Maximizing DISCO profit in active distribution networks by optimal planning of energy storage systems and distributed generators. Renew. Sustain. Energy Rev. 2016, 71, 365-372. [CrossRef]

73. Bongers, T.; Kellermann, J.; Franz, M.; Moser, A. Impact of curtailment of renewable energy sources on high voltage network expansion planning. In Proceedings of the Power Systems Computation Conference, Genoa, Italy, 20-24 June 2016; pp. 1-8.

74. Tarôco, C.G.; Takahashi, R.H.C.; Carrano, E.G. Multi-objective planning of power distribution networks with facility location for distributed generation. Electr. Power Syst. Res. 2016, 141, 562-571. [CrossRef]

75. Santos, S.F.; Fitiwi, D.Z.; Shafie-Khah, M.; Bizuayehu, A.W.; Cabrita, C.M.P.; Catalão, J.P.S. New multi-stage and stochastic mathematical model for maximizing RES hosting capacity-part II: Numerical results. IEEE Trans. Sustain. Energy 2016, 8, 320-330. [CrossRef]

76. Wei, C.; Fu, Y.; Li, Z.; Jiang, Y. Optimal DG penetration rate planning based on S-OPF in active distribution network. Neurocomputing 2016, 174, 514-521. [CrossRef]

77. Kanwar, N.; Gupta, N.; Niazi, K.R.; Swarnkar, A.; Bansal, R.C. Simultaneous allocation of distributed energy resource using improved particle swarm optimization. Appl. Energy 2016, 185, 1684-1693. [CrossRef]

78. Shojaabadi, S.; Abapour, S.; Abapour, M.; Nahavandi, A. Optimal planning of plug-in hybrid electric vehicle charging station in distribution network considering demand response programs and uncertainties. IET Gener. Transm. Distrib. 2016, 10, 3330-3340. [CrossRef]

79. Ahmadian, A.; Sedghi, M.; Aliakbar-Golkar, M.; Fowler, M.; Elkamel, A. Two-layer optimization methodology for wind distributed generation planning considering plug-in electric vehicles uncertainties: A flexible active-reactive power approach. Energy Convers. Manag. 2016, 124, 231-246. [CrossRef]

80. Shu, W.; Yan, X.; Zhao, Y.; Zhao, J.; Yao, W.; Luo, F.; Wang, Y. A stochastic collaborative planning approach for electric vehicle charging stations and power distribution system. In Proceedings of the IEEE Power and Energy Society General Meeting, Boston, MA, USA, 17-21 July 2016; pp. 1-5.

81. Zeng, B.; Wen, J.; Shi, J.; Zhang, J.; Zhang, Y. A multi-level approach to active distribution system planning for efficient renewable energy harvesting in a deregulated environment. Energy 2016, 96, 614-624. [CrossRef]

82. Xiang, Y.; Liu, J.; Li, R.; Li, F.; Gu, C.; Tang, S. Economic planning of electric vehicle charging stations considering traffic constraints and load profile templates. Appl. Energy 2016, 178, 647-659. [CrossRef]

83. Ahmadian, A.; Sedghi, M.; Aliakbar-Golkar, M. Fuzzy load modeling of plug-in electric vehicles for optimal storage and DG planning in active distribution network. IEEE Trans. Veh. Technol. 2016, 66, 3622-3631. [CrossRef]

84. Arasteh, H.; Sepasian, M.S.; Vahidinasab, V.; Siano, P. SoS-based multiobjective distribution system expansion planning. Electr. Power Syst. Res. 2016, 141, 392-406. [CrossRef]

85. Xiang, Y.; Yang, W.; Liu, J.; Li, F. Multi-objective distribution network expansion incorporating electric vehicle charging stations. Energies 2016, 9, 909. [CrossRef]

86. Ahmadigorji, M.; Amjady, N.; Dehghan, S. A novel two-stage evolutionary optimization method for multiyear expansion planning of distribution systems in presence of distributed generation. Appl. Soft Comput. 2016, 52, 1098-1115. [CrossRef]

87. Daghi, M.; Sedghi, M.; Ahmadian, A.; Aliakbar-Golkar, M. Factor analysis based optimal storage planning in active distribution network considering different battery technologies. Appl. Energy 2016, 183, 456-469. [CrossRef]

88. Liu, W.; Xu, H.; Niu, S. An integrated planning method of active distribution system considering decentralized voltage control. In Proceedings of the IEEE Power and Energy Society General Meeting, Boston, MA, USA, 17-21 July 2016; pp. 1-5.

89. Xing, H.; Cheng, H.; Zhang, Y.; Zeng, P. Active distribution network expansion planning integrating dispersed energy storage systems. IET Gener. Transm. Distrib. 2016, 10, 638-644. [CrossRef]

90. Sandhu, K.S.; Mahesh, A. A new approach of sizing battery energy storage system for smoothing the power fluctuations of a PV/wind hybrid system. Int. J. Energy Res. 2016, 40, 1221-1234. [CrossRef] 
91. Esmaeeli, M.; Kazemi, A.; Shayanfar, H.; Chicco, G.; Siano, P. Risk-based planning of the distribution network structure considering uncertainties in demand and cost of energy. Energy 2017, 119, 578-587. [CrossRef]

92. Sardi, J.; Mithulananthan, N.; Gallagher, M.; Hung, D.Q. Multiple community energy storage planning in distribution networks using a cost-benefit analysis. Appl. Energy 2017, 190, 453-463. [CrossRef]

93. Ahmadian, A.; Sedghi, M.; Elkamel, A.; Aliakbar-Golkar, M.; Fowler, M. Optimal WDG planning in active distribution networks based on possibilistic-probabilistic PEVS load modelling. IET Gener. Transm. Distrib. 2017, 11, 865-875. [CrossRef]

94. Liu, W.; Niu, S.; Huiting, X. Optimal planning of battery energy storage considering reliability benefit and operation strategy in active distribution system. J. Mod. Power Syst. Clean Energy 2017, 5, 177-186. [CrossRef]

95. Karagiannopoulos, S.; Aristidou, P.; Hug, G. Hybrid approach for planning and operating active distribution grids. IET Gener. Transm. Distrib. 2017, 11, 685-695. [CrossRef]

96. Humayd, A.S.B.; Bhattacharya, K. Distribution system planning to accommodate distributed energy resources and PEVS. Electr. Power Syst. Res. 2017, 145, 1-11. [CrossRef]

97. Zou, B.; Wang, J.; Wen, F. Optimal investment strategies for distributed generation in distribution networks with real option analysis. IET Gener. Transm. Distrib. 2017, 11, 804-813. [CrossRef]

98. Mokryani, G.; Hu, Y.; Pillai, P.; Rajamani, H.S. Active distribution networks planning with high penetration of wind power. Renew. Energy 2017, 104, 40-49. [CrossRef]

99. Zeng, B.; Feng, J.; Zhang, J.; Liu, Z. An optimal integrated planning method for supporting growing penetration of electric vehicles in distribution systems. Energy 2017, 126, 273-284. [CrossRef]

100. Kanwar, N.; Gupta, N.; Niazi, K.R.; Swarnkar, A. Optimal allocation of DGs and reconfiguration of radial distribution systems using an intelligent search-based TLBO. Electr. Power Compon. Syst. 2017, 45, 476-490. [CrossRef]

101. Pombo, A.V.; Murta-Pina, J.; Pires, V.F. Multiobjective formulation of the integration of storage systems within distribution networks for improving reliability. Electr. Power Syst. Res. 2017, 148, 87-96. [CrossRef]

102. Ganguly, S.; Dipanjan, S. Distributed generation allocation with on-Load tap changer on radial distribution networks using adaptive genetic algorithm. Appl. Soft Comput. 2017, 59, 45-67. [CrossRef]

103. Mokryani, G.; Hu, Y.; Papadopoulos, P.; Niknam, T.; Aghaei, J. Deterministic approach for active distribution networks planning with high penetration of wind and solar power. Renew. Energy 2017, 113, 942-951. [CrossRef]

104. Nick, M.; Rachid, C.; Mario, P. Optimal planning of distributed energy storage systems in active distribution networks embedding grid reconfiguration. IEEE Trans. Power Syst. 2017, 99, 1. [CrossRef]

105. Awad, A.S.A.; EL-Fouly, T.H.M.; Salama, M.M.A. Optimal ESS allocation for benefit maximization in distribution networks. IEEE Trans. Smart Grid 2017, 8, 1668-1678. [CrossRef]

106. Kumar, D.; Samantaray, S.R.; Kamwa, I. MOSOA-based multiobjective design of power distribution systems. IEEE Syst. J. 2017, 11, 1182-1195. [CrossRef]

107. Tanwar, S.S.; Khatod, D.K. Techno-economic and environmental approach for optimal placement and sizing of renewable DGs in distribution system. Energy 2017, 127, 52-67. [CrossRef]

108. Pilo, F.; Pisano, G.; Soma, G.G. Optimal coordination of energy resources with a two-stage online active management. IEEE Trans. Ind. Electron. 2011, 58, 4526-4537. [CrossRef]

109. Mehmood, K.K.; Khan, S.U.; Lee, S.-J.; Haider, Z.M.; Rafique, M.K.; Kim, C.-H. A real-time optimal coordination scheme for the voltage regulation of a distribution network including an OLTC, capacitor banks, and multiple distributed energy resources. Int. J. Electr. Power Energy Syst. 2018, 94, 1-14. [CrossRef]

110. Koutsoukis, N.C.; Siagkas, D.O.; Georgilakis, P.S.; Hatziargyriou, N.D. Online reconfiguration of active distribution networks for maximum integration of distributed generation. IEEE Trans. Autom. Sci. Eng. 2017, 14, 437-448. [CrossRef]

111. Carr, S.; Premier, G.C.; Guwy, A.J.; Dinsdale, R.M. Energy storage for active network management on electricity distribution networks with wind power. IET Renew. Power Gener. 2013, 8, 249-259. [CrossRef]

112. Huang, D.; Billinton, R. Effects of load sector demand side management applications in generating capacity adequacy assessment. IEEE Trans. Power Syst. 2012, 27, 335-343. [CrossRef]

113. Davies, D.L.; Bouldin, D.W. A cluster separation measure. IEEE Trans. Pattern Anal. Mach. Intell. 1979, 1, 224-227. [CrossRef] [PubMed]

114. Gao, C.; Pedrycz, W.; Miao, D.Q. Rough subspace-based clustering ensemble for categorical data. Soft Comput. 2013, 17, 1643-1658. [CrossRef] 
115. Xie, X.L.; Beni, G. A validity measure for fuzzy clustering. IEEE Trans. Pattern Anal. Mach. Intell. 1991, 13, 841-847. [CrossRef]

116. Candler, W.; Norton, R.D. Multilevel Programming and Development Policy; The World Bank: Washington, DC, USA, 1977; Volume 258, pp. 1-40.

117. Celli, G.; Ghiani, E.; Mocci, S.; Pilo, F.; Soma, G.G.; Vertuccio, C. Probabilistic planning of multi-microgrids with optimal hybrid multi-generation sets. In Proceedings of the CIGRÉ, Paris, France, 21-26 August 2016; pp. 1-10.

118. Farzin, H.; Moeini-Aghtaie, M.; Fotuhi-Firuzabad, M. A hierarchical scheme for outage management in multi-microgrids. Int. Trans. Electr. Energy Syst. 2016, 26, 2023-2037. [CrossRef]

119. Hasanvand, S.; Nayeripour, M.; Waffenschmidt, E.; Fallahza-deh-Abarghouei, H. A new approach to transform an existing distribution network into a set of micro-grids for enhancing reliability and sustainability. Appl. Soft Comput. 2017, 52, 120-134. [CrossRef]

120. Fathi, M.; Bevrani, H. Adaptive energy consumption scheduling for connected microgrids under demand uncertainties. IEEE Trans. Power Deliv. 2013, 28, 1576-1583. [CrossRef]

121. Wang, Z.; Chen, B.; Wang, J.; Begovic, M.M.; Chen, C. Coordinated energy management of networked microgrids in distribution systems. IEEE Trans. Smart Grid 2015, 6, 45-53. [CrossRef]

122. Wu, J.; Guan, X. Coordinated multi-microgrids optimal control algorithm for smart distribution management system. IEEE Trans. Smart Grid 2013, 4, 2174-2181. [CrossRef]

123. Liu, J.; Gao, H.; Ma, Z.; Li, Y. Review and prospect of active distribution system planning. J. Mod. Power Syst. Clean Energy 2015, 3, 457-467. [CrossRef]

124. Konig, J.; Nordstrom, L. Assessing impact of ICT system quality on operation of active distribution grids. In Proceedings of the IEEE Bucharest PowerTech, Bucharest, Romania, 28 June-2 July 2009; pp. 1-8.

125. Fan, M.; Zhang, Z.; Tian, T. The analysis of the information needed for the planning of active distribution system. In Proceedings of the International Conference and Exhibition on Electricity Distribution, Stockholm, Sweden, 10-13 June 2013; pp. 1-4.

126. Shen, Y.; Xu, J.; Yue, Y.; Zhu, S.; Li, Q. Comprehensive coordinated model of active distribution network planning. In Proceedings of the IEEE International Conference on Power System Technology, Wollongong, NSW, Australia, 28 September-1 October 2016; pp. 1-6.

127. Yang, T.; Huang, Z.; Pen, H.; Zhang, Y. Optimal planning of communication system of CPS for distribution network. J. Sens. 2017, 2017, 9303989. [CrossRef]

(C) 2017 by the authors. Licensee MDPI, Basel, Switzerland. This article is an open access article distributed under the terms and conditions of the Creative Commons Attribution (CC BY) license (http://creativecommons.org/licenses/by/4.0/). 